\title{
A Central Role for Thiols in Plant Tolerance to Abiotic Stress
}

\author{
Lyuben Zagorchev ${ }^{1}$, Charlotte E. Seal ${ }^{2}$, Ilse Kranner ${ }^{3}$ and Mariela Odjakova ${ }^{1, *}$
}

1 Department of Biochemistry, Faculty of Biology, Sofia University, 1164 Sofia, Bulgaria; E-Mail: lzagortchev@yahoo.co.uk

2 Seed Conservation Department, Royal Botanic Gardens Kew, Wakehurst Place, Ardingly, West Sussex, RH17 6TN, UK; E-Mail: c.seal@kew.org

3 Institute of Botany, University of Innsbruck, Sternwartestraße 15, A-6020 Innsbruck, Austria; E-Mail: ilse.kranner@uibk.ac.at

* Author to whom correspondence should be addressed; E-Mail: modjakova@biofac.uni-sofia.bg; Tel.: +359-2-816-7391.

Received: 4 February 2013; in revised form: 28 February 2013 / Accepted: 14 March 2013 / Published: 2 April 2013

\begin{abstract}
Abiotic stress poses major problems to agriculture and increasing efforts are being made to understand plant stress response and tolerance mechanisms and to develop new tools that underpin successful agriculture. However, the molecular mechanisms of plant stress tolerance are not fully understood, and the data available is incomplete and sometimes contradictory. Here, we review the significance of protein and non-protein thiol compounds in relation to plant tolerance of abiotic stress. First, the roles of the amino acids cysteine and methionine, are discussed, followed by an extensive discussion of the low-molecular-weight tripeptide, thiol glutathione, which plays a central part in plant stress response and oxidative signalling and of glutathione-related enzymes, including those involved in the biosynthesis of non-protein thiol compounds. Special attention is given to the glutathione redox state, to phytochelatins and to the role of glutathione in the regulation of the cell cycle. The protein thiol section focuses on glutaredoxins and thioredoxins, proteins with oxidoreductase activity, which are involved in protein glutathionylation. The review concludes with a brief overview of and future perspectives for the involvement of plant thiols in abiotic stress tolerance.
\end{abstract}

Keywords: cysteine; glutaredoxin; glutathione; glutathionylation; phytochelatins; reactive oxygen species; redox state; signalling; sulphur metabolism; thioredoxin 
Abbreviations: ABA, abscisic acid; ASC, ascorbate; ASCPx, ascorbate peroxidase; Cys, cysteine; CySS, cystine, cysteine-disulphide; DHA, dehydroascorbate; DHAR, dehydroascorbate reductase; EGSSG/2 GSH, half-cell reduction potential of the glutathione disulphide-glutathione redox couple; GPx, glutathione peroxidase; GR, glutathione reductase; GRX, glutaredoxin; GSH, glutathione; GSNO, S-nitrosoglutathione; GSSG, glutathione disulphide; GST, glutathione-S-transferase; hGSH, homoglutathione; hGSSG, homoglutathione disulphide; HSP, heat shock protein; MDHAR, monodehydroascorbate reductase; Met, methionine; MSR, methionine sulfoxide reductase; NTRC, thioredoxin reductase type $\mathrm{C}$; PC, phytochelatins; PCS, phytochelatin synthetase; PRX, thiol peroxidase; RNS, reactive nitrogen species; ROS, reactive oxygen species; SAM, S-adenosyl methionine; SAT, serine acetyltransferase; SOD, superoxide dismutase; TRX, thioredoxin; TTL, tetratricopeptide thioredoxin-like.

\section{Introduction}

The understanding of the mechanisms of plant stress tolerance is key to the successful selection of tolerant crops in growth areas affected by environmental pollution and climate change, which is predicted to increase drought and salinisation. Recently, a number of "omics" studies, including transcriptional regulation of stress-related genes, were conducted [1,2], and proteomic studies have identified proteins with significance to plant stress response [3,4]. However, the data still do not provide sufficient information on the particular mechanisms that underpin the stress phenome. Low-molecular-weight compounds were also found to be a key component of the plant stress response. From the 1980ies onwards [5-7], much research into biochemical stress markers was targeted to elucidate components of oxidative stress, and metabolomic studies of plant stress tolerance are now beginning to reveal a more complete picture [8].

Many of the mechanisms of abiotic stress response in plants were found to be similar, if not identical, independent of the stress factor [9]. Such non-specific stress responses may explain the cross-tolerance to various stresses of a particular resistant species or crop line. It has been established that temperature stress [10], heavy metals [11], salt stress and water deficit [12] can all lead to increased production of reactive oxygen species (ROS) with downstream alterations of oxidative signalling. Evidence is emerging that a number of non-protein and protein thiols, together with a network of sulphur-containing molecules and related compounds, also fundamentally contribute to plant stress tolerance $[13,14]$.

The aim of this review is to provide an update on the most important non-protein and protein thiols with respect to plant tolerance to abiotic stress, which are summarised in Figure 1. The sulphur-containing amino acids, cysteine (Cys), the primary product of sulphate assimilation, and methionine (Met) are discussed first, followed by a detailed discussion of the roles of the most abundant low-molecular-weight thiol, the tripeptide glutathione ( $\gamma$-glutamyl-cysteinyl-glycine; GSH), which is synthesised from Cys and the various protective mechanisms in which GSH and glutathione disulphide (GSSG) are involved in. Glutathione is a key water-soluble antioxidant and plays a central part in ROS scavenging through the GSH-ascorbate cycle and as an electron donor to glutathione peroxidase (GPx). It is the storage form and the long-distance transport form of reduced sulphur, is involved in the detoxification of heavy metals and xenobiotics [15] and in the regulation of the cell 
cycle. Lastly, protein thiols, which include thioredoxins and glutaredoxins and the glutathionylation of protein sulphydryl groups, are considered as protective and regulatory mechanisms. Despite recent progress, our knowledge of the biochemical interactions between low- and high-molecular-weight thiols and other molecules is still incomplete. However, the data available so far suggest that thiols play a central role in the abiotic stress tolerance of plants.

Figure 1. Overview of the roles of thiols in plant tolerance to abiotic stress. Potential roles of and the significance for abiotic stress tolerance are depicted by green circles next to $\mathrm{SH}$-adducts. Potential deleterious compounds are shown in red and their adducts in green font. The dotted circle represents the half-cell reduction potential of the glutathione disulphide (GSSG)/2 glutathione (GSH) redox couple. Met, methionine; Cys, cysteine; TRX, thioredoxin; GRX, glutaredoxin; PC, phytochelatins; PCS, phytochelatin synthetase; GST, glutathione-S-transferase; GPx, glutathione peroxidase; GR, glutathione reductase; DHAR, dehydroascorbate reductase; ASC, ascorbate; MDHAR, monodehydroascorbate reductase; DHA, dehydroascorbate; ASCPx, ascorbate peroxidase.

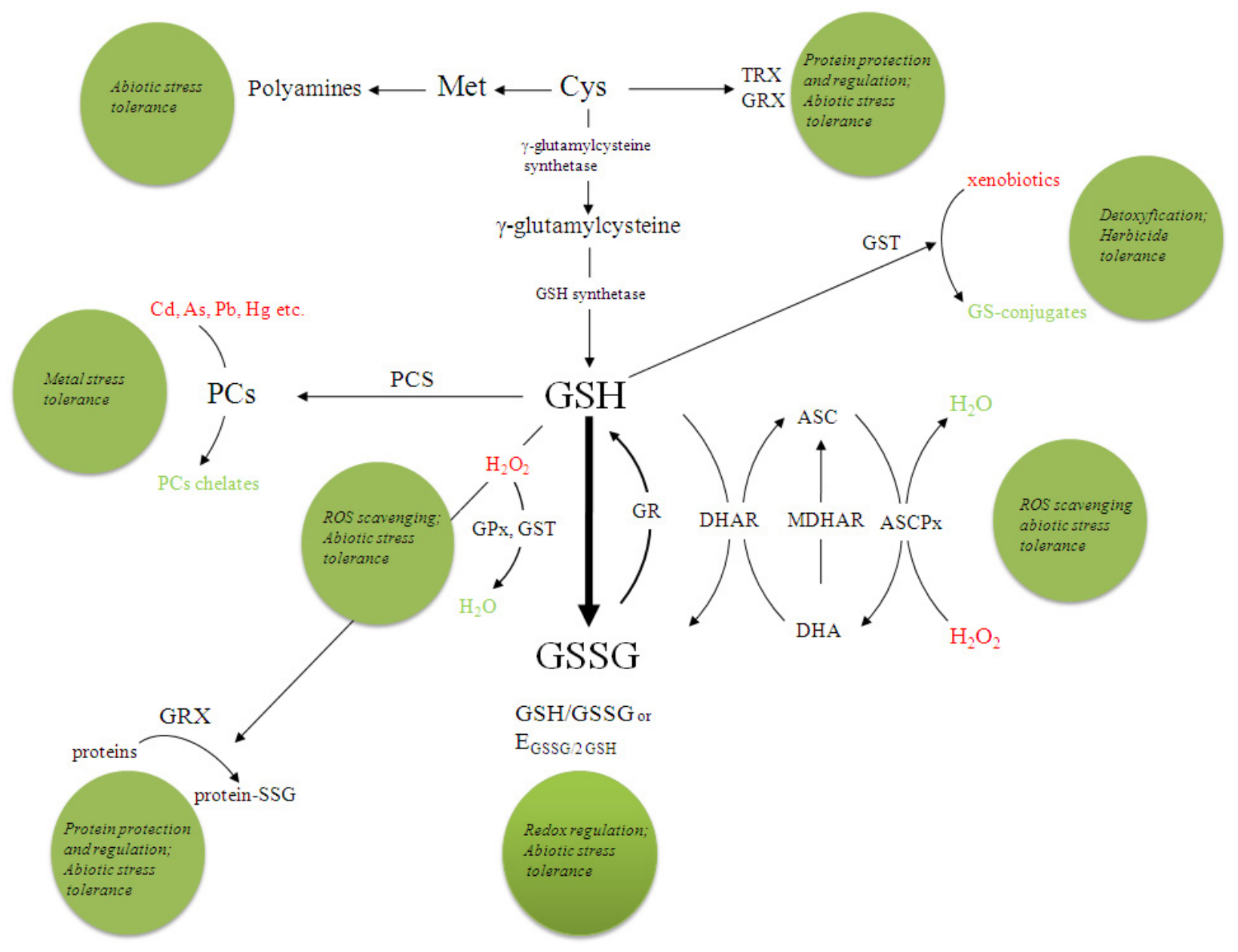




\section{Sulphur-Containing Amino Acids}

\subsection{Cysteine Biosynthesis and Free Cysteine Accumulation}

Cys is the final product of sulphate assimilation, the process by which sulphur is taken up by plants. Hence, Cys is a central metabolite that serves as a sulphur donor for the synthesis of Met, iron-sulphur clusters, some vitamins, such as thiamine and biotin, of lipoic acid and coenzyme A, GSH and thiol-containing proteins [16]. Cys is synthesised in two steps. First, o-acetylserine is formed from Ser and acetyl-CoA, catalysed by serine acetyltransferase (SAT; EC 2.3.1.30), and then, reduced sulphur in the form of $\mathrm{H}_{2} \mathrm{~S}$ is included by o-acetylserine (thiol) lyase (EC 4.2.99.8) by elimination of the acetate residue to form Cys. These two enzymes form the hetero-oligomeric Cys synthetase complex. There is a variety of Cys synthetase isoforms in protein-synthesising organelles, e.g., chloroplasts, mitochondria, and in the cytoplasm [17]. Using transgenic plants expressing or overexpressing different serine acetyltransferase (SAT) and O-acetylserine (thiol) lyase isoforms showed that the Cys synthetase complex is a primary enzyme of sulphur metabolism with significance to stress response. For example, the Cys synthetase complex appears to be involved in Cd tolerance in transgenic tobacco plants [18] and in $\mathrm{H}_{2} \mathrm{~S}$ and $\mathrm{SO}_{2}$ toxicity resistance in transgenic poplar [19].

Unstressed cells contain low concentrations of free Cys, not more than 10-30 $\mu \mathrm{M}$, but turnover rates are high [20]. The accumulation of free Cys is limited by feedback regulation of SAT, and expression of Cys-insensitive SATs is required for Cys accumulation [21]. An increase in free Cys levels in response to various abiotic stress factors has been reported [22,23]. In most studies, this increase was reported together with increased GSH concentrations, leading to the conclusion that Cys is mainly needed for the biosynthesis of sulphur-rich compounds with anti-stress activity, such as GSH and stress-related proteins. It is generally thought that at concentrations above $50 \mu \mathrm{M}$, Cys is toxic for plants [13]. Cys is a potent chelator of heavy metals ions, but Cys-metal ion complexes can trigger the Fenton reaction, thereby producing the highly toxic ${ }^{\circ} \mathrm{OH}$ radical. Furthermore, free Cys is often irreversibly oxidised to different by-products [24]. Hence, the accumulation of free Cys can lead to undesirable loss of sulphur, which potentially compromises the stress coping mechanisms of the plant. It is uncertain whether reversible formation of cystine (cysteine-disulphide; CySS) is catalysed by cystine reductase (EC 1.8.1.6) in plants, as studies of this enzyme are rare [25] and no recent reports are available for plants. On the other hand, similar enzymes were found in different organisms, including protozoa [26] and bacteria [27].

The redox potential of the CySS/2Cys couple is regarded as an important biochemical marker for the early stages of various human diseases [28] and as an important antioxidant system and regulator of the redox state in parasites [29], and the CySS /2Cys redox state may have important roles in plant stress response, too [30]. The pathways of CySS metabolism in plant cells are still unclear; Olm et al. [31] suggested that molecules such as GSH, and enzymes, such as glutathione reductase (GR), thioredoxin reductase and glutaredoxins (GRXs), could be responsible for CySS reduction. In protozoa, thioredoxin reductase has such a function [32], but several studies of glutathione reductase (GR) showed that this enzyme is not capable of reducing CySS [33]. There are large gaps in our knowledge of Cys and CySS metabolism in plants, and closing them will further enhance our understanding of plant stress response. 


\subsection{Methionine}

Similar to Cys, Met can undergo ROS-mediated oxidation to methionine sulfoxide (MetO) and this can lead to changes in protein conformation and activity [34]. The conversion of MetO to Met is mediated by Met sulfoxide reductases (MSRs; EC 1.8.4.11), a class of cytosolic and plastidic enzymes that are involved in ameliorating oxidative damage [35]. Unlike Cys, accumulation of free Met in plant cells under stress does not appear to be linked to antioxidant defence. There are few and ambiguous data on free Met accumulation under drought [36] and osmotic stress [37], whereby Met was not discriminated from valine in the latter report. Overexpression of cystathionine $\gamma$-synthase (EC 2.5.1.48) in tobacco [38] and ectopic expression of bacterial serine acetyltransferase (EC 2.3.1.30) in rice [39] led to increased levels of intracellular free Met, but these experiments were conducted with the aim to improve the nutritional qualities of the crops, considering that Met is also an essential amino acids for humans. Supplementation of the growth medium with Met improved stress survival of E. coli [40], but no similar in vitro experiments have been conducted with plant cultures.

Met is also a substrate for the synthesis of various polyamines with important roles in stress tolerance, the most prominent being putrescine, spermidine and spermine [41]. This biosynthetic pathway involves the intermediate S-adenosylmethionine (SAM) as a primary methyl donor, which further yields S-adenosyl-L-homocysteine that is metabolised to eventually regenerate Met. SAM is also a source for ethylene synthesis [42], reinforcing the pivotal role of Met in the plant stress response. Accumulation of polyamines, either free or conjugated, in response to abiotic stress and induction of the enzymes involved in their synthesis was reported in a number of case studies (reviewed in [41]). Similarly, transgenic plants expressing polyamine biosynthetic genes showed much higher stress tolerance than wild-type plants [43]. According to an extensive review by Groppa and Benavides [44], polyamines are involved in stress response and tolerance to almost every type of abiotic stress, such as salt, drought, chilling, UV, metal, ozone, wounding and, more generally, oxidative stress. Most importantly, polyamine biosynthesis does not consume sulphur and could be by-passed in a SAM independent biosynthesis; therefore, it can occur under sulphur-limited conditions [45].

\section{Glutathione}

\subsection{GSH in Plant Stress Response}

All plants contain GSH or GSH homologues, where the $C$-terminal amino acid glycine is replaced by another amino acid, such as $\beta$-alanine, serine or glutamate [15]. GSH is synthesised in two steps. First, $\gamma$-glutamyl-cysteine is formed in an ATP-dependent reaction, catalysed by glutamate-cysteine ligase, also known as $\gamma$-glutamyl-cysteine synthetase (EC 6.3.2.2), which is the rate-limiting reaction. Glutathione synthetase (EC 6.3.2.3) then catalyses the addition of glycine to $\gamma$-glutamyl-cysteine [15]. GSH synthesis can occur in the cytosol, chloroplasts and mitochondria [46], and both enzymes are encoded by single genes with alternate transcription start sites that are associated with their subcellular localisation [47]. Recently published results confirmed that the concentrations of GSH increased at least transiently in plants exposed to $\mathrm{Cd}$ [48], $\mathrm{Pb}$ [49], salt [30], drought [50] and heat stress [51].

Several studies of plants that overexpressed $\gamma$-glutamyl-cysteine synthetase or transgenic plants expressing bacterial $\gamma$-glutamyl-cysteine synthetase evaluated its effect on metal tolerance based on the 
assumption that higher levels of GSH and phytochelatins will lead to more efficient metal sequestration. Interestingly, several authors reported that increased expression of this enzyme may not be related to stress tolerance, especially $\mathrm{Cd}$ tolerance. Overexpression of $\gamma$-glutamyl-cysteine synthetase in Arabidopsis [52] and tomato [53] did not enhance resistance to $\mathrm{Cd}$ stress, despite increased levels of GSH and phytochelatins. Similarly, the expression of bacterial $\gamma$-glutamyl-cysteine synthetase in Arabidopsis did not enhance Cd tolerance and even caused Cd sensitivity [54], although some resistance to As and $\mathrm{Hg}$ was observed. Transgenic cottonwood also showed enhanced As tolerance [55]. Song et al. [56] showed that $\mathrm{Cu}$ stress lead to a two- to three-fold increase in the concentration of $\gamma$-glutamyl-cysteine synthetase in different rice varieties, with the sensitive genotype showing a greater increase. The overall conclusion was that $\mathrm{Cd}$ tolerance may rely on different factors than tolerance to other metals (see Section 3.5).

Although increased levels of GSH may be required for metal tolerance, it seems that tolerant genotypes tend to keep their $\gamma$-glutamyl-cysteine synthetase levels lower than sensitive ones. Similarly, long term water deficit in Vigna radiata caused a decrease in both $\gamma$-glutamyl-cysteine synthetase activity and its transcript levels [57] in roots and even lower activity, combined with higher mRNA levels during the recovery period. This is in disagreement with the assumption that abiotic stress tolerance involves an increase in $\gamma$-glutamyl-cysteine synthetase abundance and activity along with increases in Cys and GSH concentrations, as shown for salt stress [58]. Overall, in most, if not all, of the cited studies, glutathione synthetase expression and activity increased simultaneously with that of $\gamma$-glutamyl-cysteine synthetase. Loss of function of any of the two enzymes proved to be lethal to early developmental stages, and GSH deficiency resulted in increased sensitivity to Cd in Arabidopsis [59].

Homoglutathione (hGSH) is a homologue of $\mathrm{GSH}$, characteristic for legumes in which the $C$-terminal Gly is substituted by $\beta$-Ala and, overall, has the same functions as GSH [15]. It is regarded as an important regulator of root nodule formation, symbiotic interactions and nitrogen fixation [60], serves functions in the transport of reduced sulphur and has antioxidant activity, as GSH does. Legumes are also capable of synthesising homophytochelatins in response to heavy metal stress [61]. A study of hGSH synthetase transcript levels and activity and hGSH concentration in root nodules exposed to different stresses [62] did not reveal any significant increase in hGSH synthetase, except for mRNA levels that rose upon $\mathrm{Cd}$ and $\mathrm{H}_{2} \mathrm{O}_{2}$ treatments. In contrast, Cruz de Carvalho et al. [63] found increased mRNA levels in the leaves of a drought tolerant cowpea cultivar, encoding hGSH synthetase during drought stress and desiccation, revealing different stress response patterns than in roots. The distribution of GSH and hGSH in different plant organs is species-specific and determined by the differential expression of the corresponding synthetase genes (summarised by [64]). Other authors reported that a glyphosate-resistant soybean line showed an increase in hGSH concentration upon glyphosate treatment, whereas in a glyphosate-sensitive line, it remained unchanged or decreased slightly; and, more importantly, the hGSH/hGSSG ratio remained higher in the resistant line [65]. The latter is an example of a complete overlap of hGSH and GSH functions, which is not surprising, as hGSH replaces GSH in soybean. A comparative study between soybean and white lupin subjected to $\mathrm{Cd}$ and As [66] showed that hGSH levels (in soybean) increased significantly more than GSH levels (in white lupin). Clemente et al. [67] also suggested that GSH and hGSH play distinct roles in plant development and stress response, based on the differential hormone-mediated expression and activity of GSH and hGSH synthetases. Hence, GSH and hGSH have largely the same functions, although in 
some cases, the two homologues may be differentially affected by stress in plant species that are able to synthesise both hGSH and GSH, but the importance of such effects is still to be elucidated.

\subsection{Glutathione Redox State}

GSH is the main cellular redox buffer that keeps the intracellular environment reduced. Typically, the GSH to GSSG ratio is about 20:1 in unstressed conditions, and this ratio shifts towards GSSG upon stress, as a result of ROS scavenging under conditions that compromise the reduction of GSSG to GSH [68]. This shift contributes to the signalling pathways that lead to programmed cell death, an important mechanism of stress resistance [69]. A reducing intracellular environment is needed to maintain protein structure and function (reviewed by [70]). A high GSH/GSSG ratio is supported by GR (EC 1.6.4.2), and stress-tolerant genotypes have higher ratios than stress-sensitive ones [71,72]. The GSH/GSSG ratio also varies with developmental stage. For example, a lower GSH/GSSG ratio is needed for somatic embryogenesis compared to the stage of cell proliferation [30].

Expressing the glutathione redox state through the glutathione half-cell reduction potential $\left(\mathrm{E}_{\mathrm{GSSG} / 2 \mathrm{GSH}}\right)$ [73] takes into account the molar concentrations of GSH and GSSG instead of mere ratios. For concentration-dependent redox couples (note that two moles of GSH are required to produce one mole of GSSG), this is a critical consideration, as the concentration of GSH is important for cellular stress tolerance and viability. A clear correlation between $\mathrm{E}_{\mathrm{GSSG} / 2 \mathrm{GSH}}$ and cell viability has been demonstrated [74-76], and recently, the redox state of other low-molecular-weight thiols was also included to form a combined low-molecular-weight thiol-disulphide-based redox environment,

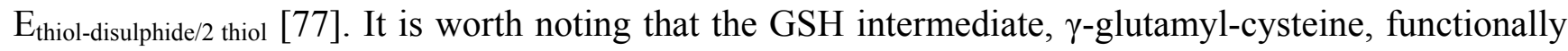
replaced GSH, at least to some extent, at optimal conditions in a GSH synthetase loss of function mutant of cyanobacteria [78]. Elevated concentrations of $\gamma$-glutamyl-cysteine and its corresponding disulphide in plants could be deleterious, as there is no known enzyme capable of reducing it, and the only way for removal of the $\gamma$-glutamyl-cysteine disulphide is by degradation [79]. The concentration of Cys could also be of great importance, especially in conditions of abiotic stress [30]. Overall, the thiol-disulphide redox state serves as a marker of stress and cell viability, with important impacts upon the signalling mechanism during abiotic [80] and biotic stress [81].

ROS and redox signalling are in part transmitted through $\mathrm{H}_{2} \mathrm{O}_{2}$, and the best characterised pathway in plants is the "classic" chloroplast retrograde pathway [80]. The main regulator of redox state in chloroplasts is the plastoquinone pool, but shifts in the glutathione redox state and ascorbate pools were also correlated with development and stress response [82]. Redox signalling also likely includes an ascorbate-based redox shuttle across the plasma membrane that could regulate ascorbate concentrations in the different cell compartments, according to the specific requirements [83]. As an electron donor required for dehydroascorbate reduction, GSH could contribute to that system. The contribution of the GSH/GSSG couple to the fine tuning of the overall cellular redox state and its involvement in transcriptional control was proposed by Noctor and Foyer [7] and confirmed later [70].

\subsection{The Ascorbate-Glutathione Cycle}

In the ascorbate-glutathione cycle, also known as the Foyer-Halliwell-Asada cycle, superoxide can be converted to $\mathrm{H}_{2} \mathrm{O}_{2}$ by superoxide dismutase (SOD, EC 1.15.1.1). Then, $\mathrm{H}_{2} \mathrm{O}_{2}$ is further detoxified 
by ascorbate peroxidase (ASPx, EC 1.11.1.11), whereby monodehydroascorbate is produced, which can spontaneously dismutate to ascorbate and dehydroascorbate [82]. Monodehydroascorbate can also be reduced to ascorbate by $\mathrm{NAD}(\mathrm{P}) \mathrm{H}$-dependent monodehydroascorbate reductase (MDHAR, EC 1.6.5.4) and dehydroascorbate reduced by GSH-dependent dehydroascorbate reductase (DHAR, EC 1.8.5.1). The latter is induced by various abiotic stresses and is thought to be critical for stress tolerance (see [84] and references therein). Abiotic stresses can simultaneously increase both the mRNA transcripts and activity of both enzymes [85], and overexpression of DHAR rather than MDHAR has been associated with stress tolerance [86]. However, a salt inducible MDHAR from the halophyte, Avicennia marina, may suffice to induce salt tolerance in transgenic plants [87]. Similar results were published for MDHAR from Malpighia glabra expressed in tobacco cells [88]. Evidence for the cooperation of various enzymes in the GSH-ascorbate cycle was demonstrated for transgenic tobacco plants, in which only those transformants showed increased tolerance to salt and cold stress that had DHAR and GR upregulated [89]. Therefore, the DHAR pathway may be less effective during sulphur starvation or in GSH-deficient mutants, but a shift from the GSH-dependent DHAR to GSH-independent MDHAR ascorbate regeneration under sulphur deficiency was not supported by experimental data. Contrary, MDHAR activity was shown to decrease in sulphur-starved plants [90].

Enhanced GSH-dependent dehydroascorbate reduction also improved tolerance to oxidative stress in DHAR transformants of Arabidopsis [91]. Interestingly, these transformants showed constitutively high DHAR activity, but also increased concentrations of both ascorbate and GSH compared to the wild-type. E. coli, expressing a tomato DHAR gene, also showed enhanced tolerance to $\mathrm{H}_{2} \mathrm{O}_{2}$, although mRNA levels in tomato plants slightly increased during cold treatment and decreased during treatment with abscisic acid (ABA) [92], and only mechanical wounding significantly increased the DHAR mRNA levels. An increase in the activity of two differentially expressed tomato DHARs was reported in response to salt and drought stress [93]. Gallie [94] concluded that non-GSH-dependent reduction of dehydroascorbate by MDHAR may be of greater importance for tolerance to at least some abiotic stresses, whereas GSH-dependent ascorbate regeneration is more important under optimal conditions, although more evidence is required before this hypothesis can be accepted.

A decrease in GR activity can affect the GSH/GSSG ratio, but also decrease the ascorbate pool and impact on ascorbate redox state [95] with an overall decrease in stress tolerance [96]. In turn, overexpression of GR [97] or increase in GR activity [98] has been related to stress tolerance. This enzyme mainly operates in the chloroplasts through cytosolic isoforms and mitochondrial isoforms are also known in higher plants. Increased GR activity was reported in response to various stresses, such as salt and Cd [summarised by 97], both in leaves and roots and in all subcellular fractions. As mentioned earlier [89], an increase in GR activity alone is not sufficient to confer stress tolerance. More likely, a coordinated and finely regulated action of all enzymes of the ascorbate-glutathione cycle in conjunction with that of other ROS-processing enzymes in all cell compartments is required for plant stress tolerance.

\subsection{Glutathione-S-Transferases}

Glutathione-S-transferases (GSTs, EC 2.5.1.18) comprise an extensive family of proteins with a great variety of functions. Up to 90 genes encoding GSTs are transcribed in different plant species, 
most of which are differentially induced by stress, and they play important parts in enzymatic thiol-dependent ROS scavenging mechanisms [99]. GSTs catalyse the conjugation of GSH to an electrophilic substrate [99], for example, they can catalyse the conversion of $\mathrm{H}_{2} \mathrm{O}_{2}$ at the expense of GSH, thereby producing GSSG. Known functions in plants include conjugation and sequestration of xenobiotics, transport of flavonoids, detoxification of ROS and organic radicals, programmed cell death under conditions of elevated ROS levels, signalling through flavonoids and participation in the fumarate synthesis during the tyrosine catabolism (reviewed by [100]).

Overexpression or heterologous expression of GSTs can contribute to abiotic stress tolerance. A chloroplastic GST from Prosopis juliflora improved drought stress tolerance in tobacco [101], and overexpression of GST in Arabidopsis increased salt tolerance [102]. A summary of recent experiments that support the role of GSTs in abiotic stress tolerance is presented in Table 1. GSTs are also good examples of genes from economically unimportant species that could be used for transformation of crops with enhanced stress tolerance. However, plant stress tolerance relies on an intricate network of various pathways, and changing only one part may produce unexpected results. For example, an Arabidopsis GST knockout mutant accumulated far more GSH than the wild-type and showed much higher tolerance to salt and drought stress [103]. In summary, GSTs comprise a large family of GSH-dependent enzymes that are involved in numerous stress-responsive mechanisms, mediating GSH functions in plant cells.

Table 1. Selected reports on glutathione-S-transferase (GST) overexpression and/or heterologous expression that enhanced abiotic stress tolerance in plants. All examples include mutational overexpression of endogenous GST or transgenesis of GSTs from wild species and basal eukaryotes with no economic significance into commercial species and model plants.

\begin{tabular}{lllc}
\hline Type of stress & Notes & Species & Reference \\
\hline Cd & GST gene from Trichoderma virens & Tobacco & {$[104]$} \\
Cold & GST gene from Choristoneura fumiferana & Arabidopsis & {$[105]$} \\
Drought & Expression of GST gene from Prosopis juliflora & Tobacco & {$[106]$} \\
Drought and salt & GST gene from Glycine soja & Tobacco & {$[101]$} \\
Heavy metals & Human GST and CYP2E1 genes & Alfalfa & {$[107]$} \\
Herbicide & Overexpression of GST & Rice & {$[108]$} \\
Salt & Overexpression of GST & Arabidopsis & {$[102]$} \\
Salt & GST gene from Salicornia brachiata & Tobacco & {$[109]$} \\
\hline
\end{tabular}

\subsection{Phytochelatins}

Phytochelatins are the best known metal ion chelators in plants and also in some fungi and invertebrates. They were first described in yeast [110] and cell cultures of Rauvolfia serpentine [111] about three decades ago. Since then, a number of reports confirmed their role in metal tolerance, and they received much attention in phytoremediation programmes [112]. Phytochelatins are oligomers of GSH characterised by the general structure ( $\gamma$-Glu-Cys $)_{n}$-Gly, whereby $n$ varies between 2 and 11 . The enzyme responsible for their synthesis is phytochelatin synthase, i.e., $\gamma$-glutamyl-cysteine transpeptidase (EC 2.3.2.15), that is activated in the presence of metal ions. The phytochelatin complexes with ions 
are sequestered in the vacuole, thus ameliorating the toxic effects of metals. Numerous studies on phytochelatins are published every year, many of which report on the correlation between increased phytochelatins levels or heterologous expression of phytochelatin-related genes and metal tolerance (summarised for the year 2012 in Table 2). Phytochelatins most effectively chelate Cd, followed by As, whereas their efficiency to chelate other metals is not so conclusive. Sulphur deficient plants may switch to non-sulphur-based tolerance mechanisms, which often involve proline [24]. However, phytochelatins appear to be essential for metal tolerance.

Table 2. Selected publications from 2012 on plant heavy metal tolerance conferred by phytochelatins. All papers relate to endogenous phytochelatin synthesis except for those with symbols.

\begin{tabular}{clc}
\hline Metal tolerance & Plant species & Reference \\
\hline As & Wolffia globosa & {$[113]$} \\
& Oryza sativa & {$[114]$} \\
& Oryza sativa & {$[115]$} \\
& Pteris vittata & {$[116]$} \\
$\mathrm{Cd}$ & Brassica juncea & {$[117]$} \\
& Arabidopsis thaliana & {$[118]^{*}$} \\
& Populus nigra & {$[119]$} \\
& Oenothera odorata & {$[120]$} \\
& Triticum aestivum & {$[121]$} \\
$\mathrm{Cd}, \mathrm{As}$ & Linum usitatissimum & {$[122]$} \\
$\mathrm{Cd}, \mathrm{Cu}, \mathrm{As}, \mathrm{Zn}$ & Nicotiana tabacum & {$[123]^{*}$} \\
$\mathrm{Mn}$ & Arabidopsis thaliana & {$[124]^{\wedge}$} \\
& Vitis vinifera & {$[125]$} \\
\hline
\end{tabular}

* heterologous expression of phytochelatin synthase gene; ^ expression of yeast phytochelatin transporters.

The role of phytochelatins may not be restricted to the chelation of potentially deleterious ions. Zhang [126] showed that salt and heat stress could lead to a significant increase in phytochelatin concentrations in leaves and, to some extent, in roots of garlic seedlings. However, this study is somewhat contradictory, and the transcript levels of phytochelatin synthase under salt or heat stress were not elevated in the same way as under metal stress. Another report by Bhargava et al. [127] on the cyanobacterium, Anabaena doliolum, also suggested that increased concentrations and the role of phytochelatins may not be stress-specific. They showed that phytochelatins may provide some protection against UV-B radiation, suggesting an antioxidant or protein thiol-protective role. The cloning and expression of phytochelatin synthase gene from Anabaena into E. coli lead to increased tolerance to metals and also to salt, heat, UV-B and herbicide stress [128]. Upregulation of the phytochelatin synthase gene was also reported in Arabidopsis subjected to drought, cold and salt stress [129]. A possible role of phytochelatins in the protection of antioxidants and proteins may explain their function in tolerance to other abiotic stresses. Nonetheless, reports on the functions of phytochelatins other than in metal chelation are scarce and care should be taken to draw conclusions from potentially spurious correlations: the expression and activity of phytochelatin synthase is induced by ABA [130], but does not necessarily require the presence of metal ions. ABA is involved in plant 
response to abiotic stress at a very high level, with downstream effects on other plant hormones [131]. Therefore, phytochelatin synthase expression and activity may be affected by stress generally.

Despite their undoubted roles in metal stress response, some authors argued that phytochelatins are not essential for long-term tolerance and hyperaccumulation, for example, in Sedum alfredii [132], a plant frequently used for phytoremediation. Here, metal accumulation and sequestration was attributed to GSH, the role of which in metal chelation was recently reviewed by Jozefczak et al. [133]. NMR studies showed that GSH itself is a potent chelator of $\mathrm{Cd}$ [134]. Considering that GSH is a phytochelatin with the overall formula ( $\gamma$-Glu-Cys) $)_{n}$-Gly, whereby $n=1$, the question arises whether phytochelatin chain length is of importance for efficient chelation. The higher $\mathrm{n}$ is, the more ions are bound [135], but this could also be achieved by high GSH concentrations - although effective chelation would require high levels of GSH synthesis. The latter study showed that the stability constant of Cd-phytochelatin complexes is three-fold higher for $n=2$ compared to GSH, increased a little more for $n=3$, but did not change significantly up to $n=5$. Hence, phytochelatins are more suitable for metal chelation then GSH. Unlike GSH, phytochelatins apparently do not form disulphides under oxidative conditions, suggesting that GSH and phytochelatins have distinct physiological functions. There is some evidence that phytochelatins may undergo S-nitrosylation [136], which could reduce the ability to chelate metals [137], but no reports exist on phytochelatin-phytochelatins disulphide redox couples, and therefore, they could be regarded as a stable form of GSH under oxidative conditions.

It is worth noting that in metal-intolerant plants, increased synthesis and accumulation of phytochelatins is not necessarily beneficial. For example, an increase in phytochelatin concentration triggered by $\mathrm{Cu}$ led to GSH depletion, resulting in more oxidative conditions [138]. This effect was far lower in a $\mathrm{Cu}$-tolerant genotype, where $\mathrm{Cu}$ concentrations of $100 \mu \mathrm{M}$ and higher resulted in increased phytochelatin concentrations without depleting GSH. Other studies also showed that GSH concentration can decrease, due to phytochelatin synthesis $[139,140]$, but these lowered GSH concentrations were not deleterious and apparently accompanied by de novo GSH synthesis [140]. Heterologous expression of a wheat phytochelatin synthase gene in rice also led to increased Cd sensitivity, which was explained by GSH depletion, due to phytochelatins production [141]. By contrast, heterologous expression of phytochelatin synthase genes was related to increased metal tolerance [123]. Generally, phytochelatins are regarded as potent metal chelators, but further studies are needed to fully understand their putative role in plant stress response and to establish if this role changes upon exposure to different metal ions.

\subsection{The Involvement of GSH in Transcriptional Control}

Besides the various functions of GSH discussed earlier, there is increasing evidence that GSH is involved in the transcriptional control of various genes. An extensive study by Queval and Foyer [142] revealed that approximately 1450 genes are regulated by low GSH levels in Arabidopsis mutant lines. However, the majority of these genes were not regulated by low ascorbate levels or high $\mathrm{H}_{2} \mathrm{O}_{2}$; an overlap of about $25 \%$ was found for genes regulated by $\mathrm{GSH}$ and $\mathrm{H}_{2} \mathrm{O}_{2}$ and even less for GSH and ascorbate. 
We now know that GSH can be transported into the nucleus in both plant and animal cells, where it participates in a nuclear glutathione cycle that contributes to the control of the cell cycle (reviewed by [143]). GSH may regulate the activity and function of nuclear proteins, including transcription factors by S-glutathionylation and also affect the structure of chromatin and the dynamics of chromatin condensation [144]. These processes have been far better studied in animals than in plants and need further elucidation. In the $\mathrm{G}_{1}$ phase of the cell cycle, when the biosynthetic activity of the cell resumes, GSH accumulates in the nucleus, and the nuclear GSH pool is far more stable than the cytoplasmic pool [145]. While the nuclear GSH can be depleted in response to oxidative stress in animal cells [146] and increased to some extent in yeast [147], very little is known about plants [148]. An example is the paper on Arabidopsis by Vivancos et al. [149], where GSH accumulation differentially affected the expression of a number of redox-related proteins. Most of the downregulated transcripts encoded heat shock proteins (HSPs) or other defensive proteins, indicating that plant cells are particularly stress sensitive at this developmental stage.

GSH may also exert its regulatory role through S-nitrosylation by $\mathrm{NO}$, thus producing S-nitrosoglutathione [GSNO; 70], linking the GSH/GSSG redox state with NO signalling pathways. NO production is triggered by different stress conditions, such as cold stress [150], $\mathrm{H}_{2} \mathrm{O}_{2}$ [151], pathogens [152], heavy metals [153] and wounding [154], and provides regulatory functions under environmental stress [155], impacting upon plant stress tolerance [156]. Over-accumulation of NO and some of it adducts can cause nitrosative stress, causing direct or indirect molecular damage, which can reduce abiotic stress tolerance [157]. GSH is a poor NO-scavenger [158], and GSNO is often regarded as a mobile source of NO and also a reactive nitrogen species (RNS) itself [159]. However, GSNO may mediate intracellular NO scavenging in a reaction that produces GSSG and $\mathrm{NO}_{3}{ }^{-}$[160]. GSNO concentration is regulated by GSNO reductase (GSNOR; EC 1.2.1.46), which catalyses the transnitrosylation from GSNO to protein thiols, thereby releasing GSH. A role for this enzyme in biotic and abiotic stress was proposed [161], although it is not conclusive whether a decrease [159] or an increase [161] in activity is associated with stress tolerance.

A key role of GSNO is to support the signalling functions of NO. As a donor of NO, GSNO is believed to promote the transnitrosylation of transcription factors, with downstream effects on transcription. Prominent examples are the NPR1-TGA1 system responsible for systemic resistance to pathogens in plants and the role of GSNO in enhancing the DNA-binding ability of the TGA1 transcription factor to the promoter region of the PR-1 gene in Arabidopsis [162]. Further evidence for this regulatory mechanism in plant defence was provided recently [163]. In contrast, blockage of the DNA binding properties of the AtMYB2 transcription factor, whose activity is induced by ABA and salt stress, occurred upon S-nitrosylation of a specific Cys-residue [164]. Wounding led to a significant increase in GSNO levels in Arabidopsis [165], but GSNO is also involved in salt stress tolerance (reviewed by [166]), as shown by Wang [167], by preventing electrolyte leakage from Arabidopsis callus.

In summary, GSH is a key ROS scavenger and major cellular redox buffer; it is a pivotal part of stress signalling pathways and has important roles in the regulation of the cell cycle. 


\section{Protein Thiols}

\subsection{Thioredoxins and Glutaredoxins}

Thioredoxins (TRX) and glutaredoxins (GRX) are among the most potent protein-based protection mechanisms [168] and occur in most organisms, from bacteria (E. coli) to higher plants and animals. Both proteins are thiol oxidoreductases with a pair of Cys residues that provide reducing power to a variety of stress-related enzymes, like thiol peroxidase, methionine sulfoxide reductase (MSR) and arsenate reductases, or exert direct thiol-disulphide oxidoreductase activity to various protein targets. While GRX are directly reduced by GSH to produce GSSG, the reduction of TRX requires different reductases, depending on the cellular compartment. Cytosolic and mitochondrial TRX require compartment-specific NADPH-dependent TRX reductases [169], and plastid TRX are reduced by ferredoxin/TRX reductase [170].

The number of TRX genes may vary between plant species from 60 to 70 in rice and Arabidopsis to 11 in sorghum, and the number of genes expressing a TRX family may also differ from species to species [171]. It has been suggested that this enrichment of TRX genes in the genome is the reason why their transcriptional control varies substantially, depending on species and stress factor. Abiotic stresses elevate TRX either on the gene and/or protein level. A proteomics study showed that putative TRX and GRX genes were upregulated in rice under $\mathrm{Cu}$ stress [56]. The fold increase was also substantially higher in a $\mathrm{Cu}$ tolerant line than in a sensitive line, and a similar correlation was reported for salt-resistant and salt-sensitive barley genotypes [172]. In a genome-wide study of rice, Nuruzzaman et al. [171] showed significant differences in the TRX gene expression in conditions of biotic and abiotic stress. Interestingly, cold stress seemed to downregulate most TRX genes, but drought stress led to upregulation, at least at the earlier stages of the stress treatment. However, it should not be accepted a priori that a particular stress factor will necessarily lead to the upregulation of a particular TRX gene. TRX and GRX have various functions, such as chaperone activity reported for plastid TRX in tobacco [173]. As shown in Arabidopsis, the family of tetratricopeptide thioredoxin-like (TTL) proteins are essential for salt and osmotic stress tolerance, and mutations of their genes altered both stress response and development [174]. Despite the $C$-terminal thioredoxin-like domain, their activity is related to co-chaperon interactions with Hsp90 and Hsp70 [175]. Other proteins related to TRX or GRX may also exhibit chaperone-like functions and confer stress tolerance. Thioredoxin reductase type C (NTRC) in Arabidopsis underwent heat-shock induced oligomerization and exhibited holdase or foldase chaperone functions to provide thermotolerance [176]. It was found that the full-length cDNA of NTRC encoded TRX motifs additionally to the TR motif. It seems that NTRC is a good example of a protective protein with multiple functions and different roles, depending on the available substrate, such as reduction of protein disulphide bonds under oxidising conditions or chaperone functions to non-Cys proteins. As proposed by Chae et al. [176], this is an example of "functional promiscuity" or acquisition of a novel function without losing the primary one. In contrast, the TTL protein family may be an example of the opposite function. Overall, the NADPH-dependent TRX and GRX systems were shown to belong to the most prominent players in stress protection among both thiol-containing and non-thiol proteins. 


\subsection{Glutathionylation}

Cys residues in macromolecules are extremely vulnerable to oxidative modification, such as those associated with ROS production in adverse environmental conditions. Cys residues undergo a three-step oxidation to cysteine sulphenic acid (Cys-SOH) that is reversible, then irreversible oxidation to cysteine sulphinic acid $\left(\mathrm{Cys}-\mathrm{SO}_{2} \mathrm{H}\right)$ and cysteine sulfonic acid $\left(\mathrm{Cys}-\mathrm{SO}_{3} \mathrm{H}\right)$. The irreversibility of the protein-Cys- $\mathrm{SO}_{2} \mathrm{H}$ has been questioned [177], and in Arabidopsis, sulphiredoxins are believed to have sulphinic acid reductase activity [178]. Such proteins lose their native conformation and activity and are further processed to be degraded (summarised in [179]). Glutathionylation of the first product, protein-Cys-SOH, could be produced through reaction with GSSG or be enzymatically catalysed, leading to temporary protection of Cys-residues, a reversible protection mechanism. Cys can be reformed through reaction of the residues with GRX, which strongly depends on GSH concentration and GR activity [180]. Oxidative damage was also reported for Met residues. Extensive glutathionylation and increased GRX expression are likely to enhance stress tolerance. However, neither the exact mechanism nor the physiological relevance of protein glutathionylation in plants is established to date. Most of the results were obtained in vitro, and the prevalent understanding is that the spontaneous glutathionylation by GSSG is far less likely in vivo [181]. Most of the recent data on glutathionylation of proteins in relation to stress tolerance relate to deglutathionylation and the involvement of GRX.

Colville and Kranner [14] recently reviewed the current literature on desiccation tolerant organisms, in which extreme fluctuations in water content during wetting and drying cycles are accompanied by equally extreme changes in their cellular redox state. In these organisms, protein glutathionylation is a likely contributor to protection mechanisms that confer desiccation tolerance. Upon rehydration, de-glutathionylation was suggested to be catalysed by glutaredoxins and protein disulphide bonds to be reduced through NADPH-dependent thioredoxins (Figure 2). This thiol-disulphide cycle appears to have specific importance for desiccation tolerance and may play a more general role in plant stress tolerance.

Protein glutathionylation can be regarded a post-translational regulatory mechanism with significant effects on the activity of various enzymes and transcription factors. Among the best-characterised stress-related proteins that undergo glutathionylation are the members of the annexin superfamily [182]. Annexins are membrane-associated, $\mathrm{Ca}^{2+}$-dependent proteins with putative enzymatic activity involved in signal transduction. Differential upregulation of annexin-encoding genes was related to various stress treatments [183]. Not surprisingly, glutathionylation of annexin 1 in Arabidopsis altered its $\mathrm{Ca}^{2+}$-binding affinity, which will lead to decreased function or loss of function [183]. Protein function can be altered by glutathionylation, for example, enolase and 6-phosphogluconolactase can be inhibited, whereas apoptosis signal-regulated kinase 1 can be activated [184]. As for annexin 1, it was proposed that glutathionylation may have a function in ROS sensing or in shifting signalling pathways-from $\mathrm{Ca}^{2+}$-mediated to ROS-mediated [185]. Several studies support the possibility that the activity of enzymes of the Calvin cycle and glycolysis can decrease, due to glutathionylation under oxidative stress, which may be an important regulatory mechanism of plant carbohydrate metabolism [15]. However, despite these recent findings, protein glutathionylation in plants still remains one of the poorly studied aspects in abiotic stress response. 
Figure 2. Thiol-disulphide cycle, proposed to contribute to the biochemical mechanisms that confer desiccation tolerance, involving glutathionylation of proteins, GRX and TRX. This figure is reproduced from Colville and Kranner [14], with the permission of Plant Growth Regulation. Desiccation tolerant organisms can lose more than $90 \%$ of their water without dying and revive upon rehydration, and extreme fluctuations in water content are accompanied by equally extreme changes in cellular redox state, associated with an increase in ROS levels. Red arrows: processes that may occur predominantly during desiccation; blue arrows: processes that occur primarily during rehydration. The thiol (-SH) groups of redox-active Cys residues in proteins (P; green) and glutathione $(\mathrm{G}$; yellow) are susceptible to oxidation, and in the dry state, a shift from thiols to the disulphide forms occurs as the probability for enzymatic reduction decreases with progressive water loss. Glutathionylation protects protein Cys residues from further oxidation to sulphenic $(\mathrm{PSOH})$, sulphinic $\left(\mathrm{PSO}_{2} \mathrm{H}\right)$ and sulphonic $\left(\mathrm{PSO}_{3} \mathrm{H}\right)$ acids. Sulphenic acid can be reduced by glutathione, whereas sulphonic and sulphinic acid formation are thought to be irreversible. Glutathionylation may occur through several mechanisms, for example, through reactions between a protein thiol (PSH) and GSSG, forming protein-bound glutathione (PSSG). This will occur under conditions of severe oxidative stress when GSSG accumulates. Other mechanisms include reactions of protein thiyl radicals or sulphenic acid intermediates with GSH; glutaredoxins (GRX) can also catalyse the reaction between GS ${ }^{\circ}$ and PSH to produce PSSG (not shown), although GRXs normally act as reductants in de-glutathionylation reactions. Upon rehydration, the reduction of protein disulphides can be catalysed by thioredoxin (TRX), which is subsequently reduced by TRX reductases (NADPH-dependent thioredoxin system). The NADPH-dependent thioredoxin system operates in the cytosol and mitochondria, where TRX reductases utilise electrons supplied by NADPH, which are transferred to TRX disulphide via flavoproteins (FAD). In chloroplasts, TRX reductases may use ferredoxin as an electron donor. Moreover, upon rehydration GRXs can reduce PSSG, leading to the formation of a mixed disulphide between GSSG and GRX. This is reduced by GSH, and the resulting GSSG is reduced by GR (NADPH-dependent glutaredoxin system). The active site of GRXs can either have one (monothiol) or two (dithiol) catalytic Cys residues; only the monothiol mechanism for PSSG reduction is shown.

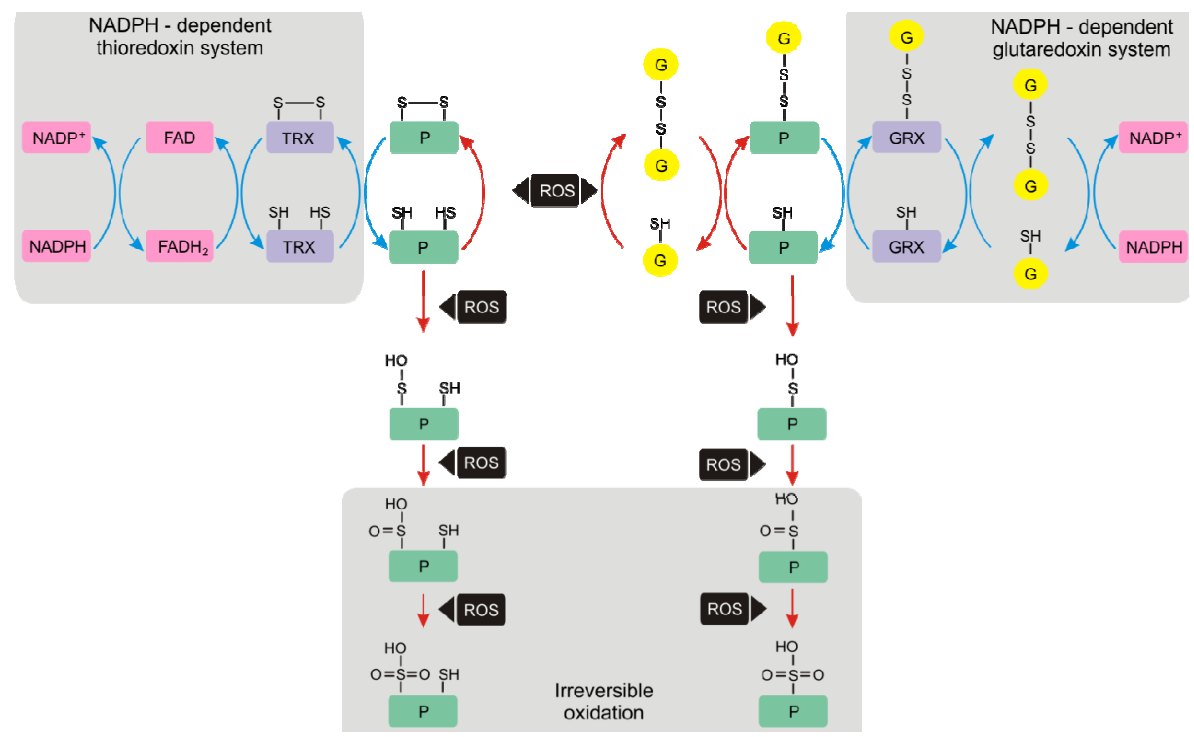




\section{Conclusions and Future Perspectives}

Areas of arable land available to an ever-increasing human population are on the decrease, and more stress tolerant crops could support future farming. Independent of the strategy used to improve crop tolerance - either by marker-assisted selection, recruitment of new potential crop species or gene transformation approaches, an in-depth understanding of the mechanisms of stress tolerance is required. Plant thiols are apparently involved in plant response to almost all stress factors, and their accumulation, redox status and regulation are key to plant stress tolerance. Minor changes in gene expression or redox state could define the difference between tolerant and susceptible genotypes or species. Despite the recent progress in the research into plant thiols, there are still many open questions. For example, the regulation of thiol biosynthesis, the maintenance of their redox state and the interconnections between different biochemical pathways are not fully understood. Nonetheless, plant thiols and plant sulphur metabolism generally deserves attention with a view to improving agricultural practice in stressful environments.

\section{Acknowledgments}

Support from COST Action FA0901 "Putting Halophytes to Work - From Genes to Ecosystems" is gratefully acknowledged. The Royal Botanic Gardens, Kew, receive grant-in-aid from DEFRA.

\section{Conflict of Interest}

The authors declare no conflict of interest.

\section{References}

1. Urano, K.; Kurihara, Y.; Seki, M.; Shinozaki, K. "Omics" analyses of regulatory networks in plant abiotic stress responses. Curr. Opin. Plant Biol. 2010, 13, 132-138.

2. Todaka, D.; Nakashima, K.; Shinozaki, K.; Yamaguchi-Shinozaki, K. Towards understanding transcriptional regulatory networks in abiotic stress responses and tolerance in rice. Rice 2012, 5, $1-9$.

3. Evers, D.; Legay, S.; Lamoureux, D.; Hausman, J.F.; Hoffmann, L.; Renaut, J. Towards a synthetic view of potato cold and salt stress response by transcriptomic and proteomic analyses. Plant Mol. Biol. 2012, 78, 503-514.

4. Sarhadi, E.; Bazargani, M.M.; Sajise, A.G.; Abdolahi, S.; Vispo, N.A.; Arceta, M.; Nejad, G.M.; Singh, R.K.; Salekdeh, G.H. Proteomic analysis of rice anthers under salt stress. Plant Physiol. Bioch. 2012, 58, 280-287.

5. Cheesman, J.M. Mechanisms of salinity tolerance in plants. Plant Physiol. 1988, 87, 547-550.

6. Hell, R. Molecular physiology of plant sulfur metabolism. Planta 1997, 202, 138-148.

7. Noctor, G.; Foyer, C.H. Ascorbate and glutathione: Keeping active oxygen under control. Annu. Rev. Plant Physiol. Plant Mol. Biol. 1998, 49, 249-279.

8. Bowne, J.; Bacic, A.; Tester, M.; Roessner, U. Abiotic Stress and Metabolomics. In Annual Plant Reviews 43: Biology of Plant Metabolomics; Hall, R.D., Ed.; Wiley-Blackwell: Oxford, UK, 2011. 
9. Pastori, J.M.; Foyer, C.H. Common components, networks, and pathways of cross-tolerance to stress. The central role of "redox" and abscisic acid-mediated controls. Plant Physiol. 2002, 129, $460-468$.

10. Chinnusamy, V.; Zhu, J.-K.; Sunkar, R. Gene regulation during cold stress acclimation in plants. Method Mol. Biol. 2010, 639, 39-55.

11. Keunen, E.; Remans, T.; Bohler, S.; Vangronsveld, J.; Cuypers, A. Metal-induced oxidative stress and plant mitochondria. Int. J. Mol. Sci. 2011, 12, 6894-6918.

12. Miller, G.; Suzuki, N.; Ciftci-Yilmaz, S.; Mittler, R. Reactive oxygen species homeostasis and signaling during drought and salinity stresses. Plant Cell Environ. 2010, 33, 453-467.

13. Meyer, A.J.; Hell, R. Glutathione homeostasis and redox regulation by sulfhydryl groups. Photosynth. Res. 2005, 86, 435-457.

14. Colville, L.; Kranner, I. Desiccation tolerant plants as model systems to study redox regulation of protein thiols. Plant Growth Regul. 2010, 62, 241-255.

15. Noctor, G.; Mhamdi, A.; Chaouch, S.; Han, Y.; Neukermans, J.; Marquez-Garcia, B.; Queval, G.; Foyer, C.H. Glutathione in plants: an integrated overview. Plant Cell Environ. 2012, 35, 454-484.

16. Hell, R.; Wirtz, M. Molecular biology, biochemistry and cellular physiology of cysteine metabolism in Arabidopsis thaliana. Arabidopsis Book 2011, 9, e0154.

17. Lewandowska, M.; Liszewska, L.; Wirtz, M.; Hell, R. Subcellular Compartmentation of Cysteine Synthesis in Plants-One Step More. In Sulfur Metabolism in Plants; de Kok, L.J., Tabe, L., Tausz, M., Hawkesford, M.J., Hoefgen, R., McManus, M.T., Norton, R.M., Rennenberg, H., Saito, K., Schnug, E., Eds.; Springer: Dordrecht, Netherlands, 2012; Volume 1, pp. 71-75.

18. Kawashima, C.G.; Noji, M.; Nakamura, M.; Ogra, Y.; Suzuki, K.T.; Saito, K. Heavy metal tolerance of transgenic tobacco plants over-expressing cysteine synthase. Biotechnol. Lett. 2004, 26, 153-157.

19. Nakamura, M.; Kuramata, M.; Kasugai, I.; Abe, M.; Youssefian, S. Increased thiol biosynthesis of transgenic poplar expressing a wheat O-acetylserine(thiol) lyase enhances resistance to hydrogen sulfide and sulfur dioxide toxicity. Plant Cell Rep. 2009, 28, 313-323.

20. Wirtz, M.; Hell, R. Functional analysis of the cysteine synthase protein complex from plants: Structural, biochemical and regulatory properties. J. Plant Physiol. 2006, 163, 273-286.

21. Tabe, L.; Wirtz, M.; Molvig, L.; Droux, M.; Hell, R. Overexpression of serine acetlytransferase produced large increases in O-acetylserine and free cysteine in developing seeds of a grain legume. J. Exp. Bot. 2010, 61, 721-733.

22. Harms, K.; von Ballmoos, P.; Brunold, C.; Höfgen, R.; Hesse, H. Expression of a bacterial serine acetyltransferase in transgenic potato plants leads to increased levels of cysteine and glutathione. Plant J. 2000, 22, 335-343.

23. Ruiz, J.; Blumwald, E. Salinity-induced glutathione synthesis in Brassica napus. Planta 2002, 214, 965-969.

24. Bashir, H.; Ahmad, J.; Bagheri, R.; Nauman, M.; Qureshi, M.I. Limited sulfur resource forces Arabidopsis thaliana to shift towards non-sulfur tolerance under cadmium stress. Environ. Exp. Bot. 2012, doi:10.1016/j.envexpbot.2012.05.004.

25. Romano, A.H.; Nickerson, W.J. Cystine reductase of pea seeds and yeasts. J. Biol. Chem. 1954, 208, 409-416. 
26. Jeelani, G.; Husain, A.; Sato, D.; Ali, V.; Suematsu, M.; Soga, T.; Nozaki, T. Two atypical L-cysteine-regulated NADPH-dependent oxidoreductases involved in redox maintenance, L-cystine and iron reduction, and metronidazole activation in the enteric protozoan Entamoeba histolytica. J. Biol. Chem. 2010, 285, 26889-26899.

27. Helmann, J.D. Bacillithiol, a new player in bacterial redox homeostasis. Antioxid. Redox Sign. 2011, 15, 123-133.

28. Iyer, S.S.; Ramirez, A.M.: Ritzenthaler, J.D.; Torres-Gonzalez, E.; Roser-Page, S.; Mora, A.L.; Brigham, K.L.; Jones, D.P.; Roman, J.; Rojas, M. Oxidation of extracellular cysteine/cystine redox state in bleomycin-induced lung fibrosis. Am. J. Physiol. Lung Cell. Mol. Physiol. 2009, 296, 37-45.

29. Krauth-Siegel, R.L.; Leroux, A.E. Low-molecular-mass antioxidants in parasites. Antioxid. Redox Sign. 2012, 17, 583-607.

30. Zagorchev, L.; Seal, C.E.; Kranner, I.; Odjakova, M. Redox state of low-molecular-weight thiols and disulphides during somatic embryogenesis of salt-treated suspension cultures of Dactylis glomerata L. Free Radic. Res. 2012, 46, 656-664.

31. Olm, E.; Fernandes, A.P.; Hebert, C.; Rundlöf, A.K.; Larsen, E.H.; Danielsson, O.; Björnstedt, M. Extracellular thiol-assisted selenium uptake dependent on the $\mathrm{x}(\mathrm{c})$-cystine transporter explains the cancer-specific cytotoxicity of selenite. Proc. Natl. Acad. Sci. USA 2009, 106, 11400-11405.

32. Brown, D.M.; Upcroft, J.A.; Upcroft, P. A thioredoxin reductase-class of disulphide reductase in the protozoan parasite Giardia duodenalis. Mol. Biochem. Parasit. 1996, 83, 211-220.

33. Arias, D.G.; Marquez, V.E.; Beccaria, A.J.; Guerrero, S.A.; Iglesias, A.A. Purification and characterization of a glutathione reductase from Phaeodactylum tricornutum. Protist 2010, 161, 91-101.

34. Dos Santos, C.V.; Cuiné, S.; Rouhier, N.; Rey, P. The Arabidopsis plastidic methionine sulfoxide reductase B proteins. Sequence and activity characteristics, comparison of the expression with plastidic methionine sulfoxide reductase $\mathrm{A}$, and induction by photooxidative stress. Plant Physiol. 2005, 138, 909-922.

35. Cabreiro, F.; Picot, C.R.; Friguet, B.; Petropoulos, I. Methionine sulfoxide reductases. Ann. N. Y. Acad. Sci. 2006, 1067, 37-44.

36. Good, A.G.; Zaplachinski, S.T. The effects of drought stress on free amino acid accumulation and protein synthesis in Brassica napus. Physiol. Plantarum. 1994, 90, 9-14.

37. Gzik, A. Accumulation of proline and pattern of alpha-amino acids in sugar beet plants in response to osmotic, water and salt stress. Environ. Exp. Bot. 1996, 36, 29-38.

38. Hacham, Y.; Matityahu, I.; Schuster, G.; Amir, R. Overexpression of mutated forms of aspartate kinase and cystathionine $\gamma$-synthase in tobacco leaves resulted in the high accumulation of methionine and threonine. Plant J. 2008, 54, 260-271.

39. Nguyen, H.C.; Hoefgen, R.; Hesse, H. Improving the nutritive value of rice seeds: elevation of cysteine and methionine contents in rice plants by ectopic expression of a bacterial serine acetyltransferase. J. Exp. Bot. 2012, 63, 5991-6001.

40. Jozefczuk, S.; Klie, S.; Catchpole, G.; Szymanski, J.; Cuadros-Inostroza, A.; Steinhauser, D.; Selbig, J.; Willmitzer, L. Metabolomic and transcriptomic stress response of Escherichia coli. Mol. Syst. Biol. 2010, 6, 1-16. 
41. Alcázar, R.; Altabella, T.; Marco, F.; Bortolotti, C.; Reymond, M.; Koncz, C.; Carrasco, P.; Tiburcio, A.F. Polyamines: Molecules with regulatory functions in plant abiotic stress tolerance. Planta. 2010, 231, 1237-1249.

42. De Poel, B.V.; Bulens, I.; Oppermann, Y.; Hertog, M.L.A.T.M.; Nicolai, B.M.; Sauter, M.; Geeraerd, A.H. S-adenosyl-1-methionine usage during climacteric ripening of tomato in relation to ethylene and polyamine biosynthesis and transmethylation capacity. Physiol. Plantarum. 2012, early online.

43. Kasukabe, Y.; He, L.; Watakabe, Y.; Otani, M.; Shimada, T.; Tachibana, S. Improvement of environmental stress tolerance of sweet potato by introduction of genes for spermidine synthase. Plant Biotechnol. 2006, 23, 75-83.

44. Groppa, M.D.; Benavides, M.P. Polyamines and abiotic stress: Recent advances. Amino Acids 2008, 34, 35-45.

45. Martin-Tanguy, J. Metabolism and function of polyamines in plants: Recent development (new approaches). Plant Growth Regul. 2001, 100, 675-688.

46. Zechmann, B.; Müller, M. Subcellular compartmentation of glutathione in dicotyledonous plants. Protoplasma 2010, 246, 15-24.

47. Wachter, A.; Wolf, S.; Steininger, H.; Bogs. J.; Rausch, T. Differential targeting of GSH1 and GSH2 is achieved by multiple transcription initiation: Implications for the compartmentation of glutathione biosynthesis in the Brassicaceae. Plant J. 2005, 41, 15-30.

48. Gill, S.S.; Khan, N.A.; Tuteja, N. Cadmium at high dose perturbs growth, photosynthesis and nitrogen metabolism while at low dose it up regulates sulfur assimilation and antioxidant machinery in garden cress (Lepidium sativum L.). Plant Sci. 2012, 182, 112-120.

49. Estrella-Gómez, N.E.; Sauri-Duch, E.; Zapata-Pérez, O.; Santamaría, J.M. Glutathione plays a role in protecting leaves of Salvinia minima from $\mathrm{Pb}^{2+}$ damage associated with changes in the expression of SmGS genes and increased activity of GS. Environ. Exp. Bot. 2012, 75, 188-194.

50. Pyngrope, S.; Bhoomika, K.; Dubey, R.S. Reactive oxygen species, ascorbate-glutathione pool, and enzymes of their metabolism in drought-sensitive and tolerant indica rice (Oryza sativa L.) seedlings subjected to progressing levels of water deficit. Protoplasma 2013, 250, 585-600.

51. Kumar, S.; Asif, M.H.; Chakrabarty, D.; Tripathi, R.D.; Dubey, R.S.; Trivedi, P.K. Differential expression of rice lambda class GST gene family members during plant growth, development, and in response to stress conditions. Plant Mol. Biol. Rep. 2012, doi:10.1007/s11105-012-0524-5.

52. Xiang, C.; Werner, B.L.; Christensen E.M.; Oliver, D.J. The biological functions of glutathione revisited in Arabidopsis transgenic plants with altered glutathione levels. Plant Physiol. 2001, 126, 564-574.

53. Goldsbrough, P.B. Metal Tolerance in Plants: The Role of Phytochelatins and Metallothioneins. In Phytoremediation of Trace Elements; Terry, N., Banuelos, G.S., Eds.; CRC Press: Boca Raton, FL, USA, 1998; pp. 221-233.

54. Li, Y.; Dhankher, O.P.; Carreira, L.; Balish, R.S.; Meagher, R.B. Arsenic and mercury tolerance and cadmium sensitivity in Arabidopsis plants expressing bacterial $\gamma$-glutamylcysteine synthetase. Environ. Toxicol. Chem. 2005, 24, 1376-1386. 
55. LeBlanc, M.S.; Lima, A.; Montello, P.; Kim, T.; Meagher, R.B.; Merkle, S. Enhanced arsenic tolerance of transgenic Eastern cottonwood plants expressing gamma-glutamylcysteine synthetase. Int. J. Phytoremed. 2011, 13, 657-673.

56. Song, Y.; Cui, J.; Zhang, H.; Wang, G.; Zhao, F.J.; Shen, Z. Proteomic analysis of copper stress responses in the roots of two rice (Oryza sativa L.) varieties differing in $\mathrm{Cu}$ tolerance. Plant Soil. 2012, doi:10.1007/s11104-012-1458-2.

57. Sengupta, D.; Ramesh, G.; Mudalkar, S.; Kumar, K.R.R.; Kirti, P.B.; Reddy, A.R. Molecular cloning and characterization of $\gamma$-glutamyl cysteine synthetase (Vr $\gamma E C S$ ) from roots of Vigna radiata (L.) Wilczek under progressive drought stress and recovery. Plant Mol. Biol. Rep. 2012, 30, 894-903.

58. Nazar, R.; Iqbal, N.; Masood, A.; Syeed, S.; Khan, N.A. Understanding the significance of sulfur in improving salinity tolerance in plants. Environ. Exp. Bot. 2011, 70, 80-87.

59. Lim, B.; Meyer, A.J.; Cobbett, C.S. Development of glutathione-deficient embryos in Arabidopsis is influenced by the maternal level of glutathione. Plant Biol. 2011, 13, 693-697.

60. El Msehli, S.; Lambert, A.; Baldacci-Cresp, F.; Hopkins, J.; Boncompagni, E.; Smiti, S.A.; Hérouart, D.; Frendo, P. Crucial role of (homo)glutathione in nitrogen fixation in Medicago truncatula nodules. New Phytol. 2011, 192, 496-506.

61. Sobrino-Plata, J.; Ortega-Villasante, C.; Flores-Cáceres, M.L.; Escobar, C.; Del Campo, F.F.; Hernández, L.E. Differential alterations of antioxidant defenses as bioindicators of mercury and cadmium toxicity in alfalfa. Chemosphere 2009, 77, 946-954.

62. Loscos, J.; Matamoros, M.A.; Becana, M. Ascorbate and homoglutathione metabolism in common bean nodules under stress conditions and during natural senescence. Plant Physiol. 2008, 146, 1282-1292.

63. Cruz de Carvalho, M.H.; Brunet, J.; Bazin, J.; Kranner, I.; d' Arcy-Lameta, A.; Zuily-Fodil, Y.; Contour-Ansel, D. Homoglutathione synthetase and glutathione synthetase in drought-stressed cowpea leaves: Expression patterns and accumulation of low-molecular-weight thiols. J. Plant Physiol. 2010, 167, 480-487.

64. Becana, M.; Matamoros, M.A.; Udvardi, M.; Dalton, D.A. Recent insights into antioxidant defenses of legume root nodules. New Phytol. 2010, 188, 960-976.

65. Diaz Vivancos, P.; Driscoll, S.P.; Bulman, C.A.; Ying, L.; Emami, K.; Treumann, A.; Mauve, C.; Noctor, G.; Foyer, C.F. Perturbations of amino acid metabolism associated with glyphosate-dependent inhibition of shikimic acid metabolism affect cellular redox homeostasis and alter the abundance of proteins involved in photosynthesis and photorespiration. Plant Physiol. 2011, 157, 256-268.

66. Vázquez, S.; Goldsbrough, P.; Carpena, R.O. Comparative analysis of the contribution of phytochelatins to cadmium and arsenic tolerance in soybean and white lupin. Plant Physiol. Bioch. 2009, 47, 63-67.

67. Clemente, M.R.; Bustos-Sanmamed, P.; Loscos, J.; James, E.K.; Pérez-Rontomé, C.; Navascués, J.; Gay, M.; Becana, M. Thiol synthetases of legumes: Immunogold localization and differential gene regulation by phytohormones. J. Exp. Bot. 2012, 63, 3923-3934.

68. Szarka, A.; Tomasskovics, B.; Bánhegyi, G. The Ascorbate-glutathione- $\alpha$-tocopherol triad in abiotic stress response. Int. J. Mol. Sci. 2012, 13, 4458-4483. 
69. Kranner, I.; Minibayeva, F.V.; Beckett, R.P.; Seal, C.E. What is stress? Concepts, definitions and applications in seed science. New Phytol. 2010, 188, 655-673.

70. Szalai, G.; Kellos, T.; Galiba, G.; Kocsy, G. Glutathione as an antioxidant and regulatory molecule in plants under abiotic stress conditions. J. Plant Growth Regul. 2009, 28, 66-80.

71. Kocsy, G.; Kobrehel, K.; Szalai, G.; Duviau, M.P.; Buzás, Z.; Galiba, G. Abiotic stress-induced changes in glutathione and thioredoxin h levels in maize. Environ. Exp. Bot. 2004, 52, 101-112.

72. El-Shabrawi, H.; Kumar, B.; Kaul, T.; Reddy, M.K.; Singla-Pareek, S.L.; Sopory, S.K. Redox homeostasis, antioxidant defense, and methylglyoxal detoxification as markers for salt tolerance in Pokkali rice. Protoplasma 2010, 245, 85-96.

73. Schafer, F.Q.; Buettner, G.R. Redox environment of the cell as viewed through the redox state of the glutathione disulfide/glutathione couple. Free Radic. Biol. Med. 2001, 30, 1191-1212.

74. Kranner, I.; Birtić, S.; Anderson, K.; Pritchard, H.W. Glutathione half-cell reduction potential: A universal stress marker and modulator of programmed cell death? Free Radic. Biol. Med. 2006, 40, 2155-2165.

75. Seal, C.E.; Zammit, R.; Scott, P.; Flowers, T.J.; Kranner, I. Glutathione half cell reduction potential and $\alpha$-tocopherol as viability markers during the prolonged storage of Suaeda maritima seeds. Seed Sci. Res. 2010, 20, 47-53.

76. Seal, C.E.; Zammit, R.; Scott, P.; Nyamongo, D.O.; Daws, M.I.; Kranner, I. Glutathione half-cell reduction potential as a seed viability marker of the potential oilseed crop Vernonia galamensis. Ind. Crop. Prod. 2010, 32, 687-691.

77. Birtić, S.; Colville, L.; Pritchard, H.W.; Pearce, S.R.; Kranner, I. Mathematically combined half-cell reduction potentials of low-molecular-weight thiols as markers of seed ageing. Free Radic. Res. 2011, 45, 1093-1102.

78. Cameron, J.C.; Pakrasi, H.B. Glutathione facilitates antibiotic resistance and photosystem I stability during exposure to gentamicin in Cyanobacteria. Appl. Environ. Microbiol. 2011, 77, 3547-3550.

79. Creissen, G.; Firmin, J.; Fryer, M.; Kular, B.; Leyland, N.; Reynolds, H.; Pastori, G.; Wellburn, F.; Baker, N.; Wellburn, A.; Mullineaux, P. Elevated glutathione biosynthetic capacity in the chloroplasts of transgenic tobacco plants paradoxically causes increased oxidative stress. Plant Cell. 1999, 11, 1277-1291.

80. Suzuki, N.; Koussevitzky, S.; Mittler, R.; Miller, G. ROS and redox signalling in the response of plants to abiotic stress. Plant Cell Environ. 2012, 35, 259-270.

81. Dubreuil-Maurizi, C.; Poinssot, B. Role of glutathione in plant signaling under biotic stress. Plant Signal. Behaviour. 2012, 7, 210-212.

82. Foyer, C.H.; Noctor, G. Ascorbate and glutathione: The heart of the redox hub. Plant Physiol. 2011, 155, 2-18.

83. Munné-Bosch, S.; Queval, G.; Foyer, C.H. The impact of global change factors on redox signaling underpinning stress tolerance Plant Physiol. 2013, 161, 5-19.

84. Urano, J.; Nakagawa, T.; Maki, Y.; Masumura, T.; Tanaka, K.; Murata, N.; Ushimaru, T. Molecular cloning and characterization of a rice dehydroascorbate reductase. FEBS Lett. 2000, $466,107-111$. 
85. Eltelib, H.A.; Badejo, A.A.; Fujikawa, Y.; Esaka, M. Gene expression of monodehydroascorbate reductase and dehydroascorbate reductase during fruit ripening and in response to environmental stresses in acerola (Malpighia glabra). J. Plant Physiol. 2011, 168, 619-627.

86. Yin, L.; Wang, S.; Eltayeb, A.E.; Uddin, M.I.; Yamamoto, Y.; Tsuji, W.; Takeuchi, Y.; Tanaka, K. Overexpression of dehydroascorbate reductase, but not monodehydroascorbate reductase, confers tolerance to aluminum stress in transgenic tobacco. Planta 2010, 231, 609-621.

87. Kavitha, K.; George, S.; Venkataraman, G.; Parida, A. A salt-inducible chloroplastic monodehydroascorbate reductase from halophyte Avicennia marina confers salt stress tolerance on transgenic plants. Biochimie 2010, 92, 1321-1329.

88. Eltelib, H.A.; Fujikawa, Y.; Esaka, M. Overexpression of the acerola (Malpighia glabra) monodehydroascorbate reductase gene in transgenic tobacco plants results in increased ascorbate levels and enhanced tolerance to salt stress. S. Afr. J. Bot. 2012, 78, 295-301.

89. Le Martret, B.; Poage, M.; Shiel, K.; Nugent, G.D.; Dix, P.J. Tobacco chloroplast transformants expressing genes encoding dehydroascorbate reductase, glutathione reductase, and glutathione-S-transferase, exhibit altered anti-oxidant metabolism and improved abiotic stress tolerance. Plant Biotechnol. J. 2011, 9, 661-673.

90. Srivastava, S.; D'Souza, S.F. Effect of variable sulfur supply on arsenic tolerance and antioxidant responses in Hydrilla verticillata (L.f.) Royle. Ecotox. Environ. Safe. 2010, 73, 1314-1322.

91. Wang, Z.; Xiao, Y.; Chen, W.; Tang, K.; Zhang, L. Increased vitamin C content accompanied by an enhanced recycling pathway confers oxidative stress tolerance in Arabidopsis. J. Int. Plant Biol. 2010, 52, 400-409.

92. Kabir, M.H.; Han, W.; Wang, M.H. Environmental stress response of a dehydroascorbate reductase gene from tomato, and its protective role in Escherichia coli. Hort. Environ. Biotech. 2011, 52, 621-628.

93. Kabir, M.H.; Wang, M.H. Expression pattern of two dehydroascorbate reductase genes from tomato (Solanum lycopersicum L.) in response to stress. J. Korean Soc. Appl. Biol. Chem. 2010, 53, 668-676.

94. Gallie, D.R. The role of L-ascorbic acid recycling in responding to environmental stress and in promoting plant growth. J. Exp. Bot. 2013, 64, 433-443.

95. Ding, S.; Lu, Q.; Zhang, Y.; Wen, X.; Zhang, L.; Lu, C. Enhanced sensitivity to oxidative stress in transgenic tobacco plants with decreased glutathione reductase activity leads to a decrease in ascorbate pool and ascorbate redox state. Plant Mol. Biol. 2009, 69, 577-592.

96. Yousuf, P.Y.; Hakeem, K.U.R.; Chandna, R.; Ahmad, P. Role of Glutathione Reductase in Plant Abiotic Stress. In Abiotic Stress Responses in Plants; Ahmad, P., Prasad, M.N.V., Eds.; Springer: New York, NY, USA, 2012; pp. 149-158.

97. Melchiorre, M.; Robert, G.; Trippi, V.; Racca, R.; Lascano, H.R. Superoxide dismutase and glutathione reductase overexpression in wheat protoplast: Photooxidative stress tolerance and changes in cellular redox state. Plant Growth Regul. 2009, 57, 57-68.

98. Wu, H.; Wu, X.; Li, Z.; Duan, L.; Zhang, M. Physiological evaluation of drought stress tolerance and recovery in Cauliflower (Brassica oleracea L.) seedling treated with methyl jasmonate and coronatine. J. Plant Growth Regul. 2012, 31, 113-123. 
99. Chi, Y.; Cheng, Y.; Vanitha, J.; Kumar, N.; Ramamoorthy, R.; Ramachandran, S.; Jiang, S.Y. Expansion mechanisms and functional divergence of the glutathione S-transferase family in Sorghum and other higher plants. DNA Res. 2011, 18, 1-16.

100. Dixon, D.P.; Lapthorn, A.; Edwards, R. Plant glutathione transferases. Genome Biol. 2002, 3, 3004:1-3004:10.

101. George, S.; Venkataraman, G.; Parida, A. A chloroplast-localized and auxin-induced glutathione S-transferase from phreatophyte Prosopis juliflora confer drought tolerance on tobacco. J. Plant Physiol. 2010, 167, 311-318.

102. Qi, Y.C.; Liu, W.Q.; Qiu, L.Y.; Zhang, S.M.; Ma, L.; Zhang, H. Overexpression of glutathione S-transferase gene increases salt tolerance of Arabidopsis. Russ. J. Plant Physiol. 2010, 57, 233-240.

103. Chen, J.H.; Jiang, H.W.; Hsieh, E.J.; Chen, H.Y.; Chien, C.T.; Hsieh, H.L.; Lin, T.P. Drought and salt stress tolerance of an Arabidopsis glutathione S-transferase U17 knockout mutant are attributed to the combined effect of glutathione and abscisic acid. Plant Physiol. 2012, 158, $340-351$.

104. Dixit, P.; Mukherjee, P.K.; Ramachandran, V.; Eapen, S. Glutathione transferase from Trichoderma virens enhances cadmium tolerance without enhancing its accumulation in transgenic Nicotiana tabacum. PLoS One 2011, 6, e16360.

105. Huang, C.; Guo, T.; Zheng, S.C.; Feng, Q.L.; Liang, J.H.; Li, L. Increased cold tolerance in Arabidopsis thaliana transformed with Choristoneura fumiferana glutathione S-transferase gene. Biol. Plantarum. 2009, 53, 183-187.

106. Ji, W.; Zhu, Y.; Li, Y.; Yang, L.; Zhao, X.; Cai, H.; Bai, X. Over-expression of a glutathione S-transferase gene, GsGST, from wild soybean (Glycine soja) enhances drought and salt tolerance in transgenic tobacco. Biotech. Lett. 2010, 32, 1173-1179.

107. Zhang, Y.; Liu, J. Transgenic alfalfa plants co-expressing glutathione S-transferase (GST) and human CYP2E1 show enhanced resistance to mixed contaminates of heavy metals and organic pollutants. J. Hazard. Mater. 2011, 189, 357-362.

108. Hu, T.; Qy, X.; Xiao, G.; Huang, X. Enhanced tolerance to herbicide of rice plants by over-expression of a glutathione S-transferase. Mol. Breed. 2009, 24, 409-418.

109. Jha, B.; Sharma, A.; Mishra, A. Expression of SbGSTU (tau class glutathione S-transferase) gene isolated from Salicornia brachiata in tobacco for salt tolerance. Mol. Biol. Rep. 2011, 38, 4823-4832.

110. Kondo, N.; Imai, K.; Isobe, M.; Goto, T.; Murasugi, A.; Wada-Nakagawa, C.; Hayashi, Y. Cadystin $\mathrm{A}$ and $\mathrm{B}$, major unit peptides comprising cadmium binding peptides induced in a fission yeast-separation, revision of structures and synthesis. Tetrahedron Lett. 1984, 25, 3869-3872.

111. Grill, E.; Winnacker, E.L.; Zenk, M.H. Phytochelatins: The principal heavy-metal complexing peptides of higher plants. Science 1985, 230, 674-676.

112. Pal, R.; Rai, J.P.N. Phytochelatins: Peptides involved in heavy metal detoxification. Appl. Biochem. Biotech. 2010, 160, 945-963.

113. Zhang, X.; Kalle Uroic, M.; Xie, W.Y.; Zhu, Y.G.; Chen, B.D.; McGrath, S.P.; Feldmann, J.; Zhao, F.J. Phytochelatins play a key role in arsenic accumulation and tolerance in the aquatic macrophyte Wolffia globosa. Environ. Pollut. 2012, 165, 18-24. 
114. Dave, R.; Singh, P.K.; Tripathi, P.; Shri, M.; Dixit, G.; Dwivedi, S.; Chakrabarty, D.; Trivedi, P.K.; Sharma, Y.K.; Dhankher, O.P.; et al. Arsenite tolerance is related to proportional thiolic metabolite synthesis in rice (Oryza sativa L.). Arch. Environ. Con. Tox. 2013, 64, 235-242.

115. Tripathi, P.; Mishra, A.; Dwivedi, S.; Chakrabarty, D.; Trivedi, P.K.; Singh, R.P.; Tripathi, R.D; Differential response of oxidative stress and thiol metabolism in contrasting rice genotypes for arsenic tolerance. Ecotox. Environ. Saf. 2012, 79, 189-198.

116. Lei, M.; Wan, X.M.; Li, X.W.; Chen, T.B.; Liu, Y.R.; Huang, Z.C. Impacts of sulfur regulation in vivo on arsenic accumulation and tolerance of hyperaccumulator Pteris vittata. Environ. Exp. Bot. 2013, 85, 1-6.

117. Mohamed, A.A.; Castagna, A.; Ranieri, A.; di Toppi, L.S. Cadmium tolerance in Brassica juncea roots and shoots is affected by antioxidant status and phytochelatin biosynthesis. Plant Physiol. Biochem. 2012, 57, 15-22.

118. Liu, Z.; Gu, C.; Chen, F.; Yang, D.; Wu, K.; Chen, S.; Jiang, J.; Zhang, Z. Heterologous expression of a Nelumbo nucifera phytochelatin synthase gene enhances cadmium tolerance in Arabidopsis thaliana. Appl. Biochem. Biotech. 2012, 166, 722-734.

119. Iori, V.; Pietrini, F.; Massacci, A.; Zacchini, A. Induction of metal binding compounds and antioxidative defence in callus cultures of two black poplar $(P$. nigra) clones with different tolerance to cadmium. Plant Cell Tiss. Org. 2012, 108, 17-26.

120. Son, K.H.; Kim, D.Y.; Koo, N.; Kim, K.R.; Kim, J.G.; Owens, G. Detoxification through phytochelatin synthesis in Oenothera odorata exposed to Cd solutions. Environ. Exp. Bot. 2012, $75,9-15$.

121. Hentz, S.; McComb, J.; Miller, G.; Begonia, M.; Begonia, G. Cadmium uptake, growth and phytochelatin contents of Triticum aestivum in response to various concentrations of cadmium. World Environ. 2012, 2, 44-50.

122. Najmanova, J.; Neumannova, E.; Leonhardt, T.; Zitka, O.; Kizek, R.; Macek, T.; Mackova, M.; Kotrba, P. Cadmium-induced production of phytochelatins and speciation of intracellular cadmium in organs of Linum usitatissimum seedlings. Ind. Crop. Prod. 2012, 36, 536-542.

123. Shukla, D.; Kesari, R.; Mishra, S.; Dwivedi, S.; Tripathi, R.D.; Nath, P.; Trivedi, P.K. Expression of phytochelatin synthase from aquatic macrophyte Ceratophyllum demersum L. enhances cadmium and arsenic accumulation in tobacco. Plant Cell Rep. 2012, 31, 1687-1699.

124. Huang, J.; Zhang, Y.; Peng, J.S.; Zhong, C.; Yi, H.Y.; Ow, D.W.; Gong, J.W. Fission yeast HMT1 lowers seed cadmium through phytochelatin-dependent vacuolar sequestration in Arabidopsis. Plant Physiol. 2012, 158, 1779-1788.

125. Yao, Y.; Xu, G.; Mou, D.; Wang, J.; Ma, J. Subcellular Mn compartation, anatomic and biochemical changes of two grape varieties in response to excess manganese. Chemosphere 2012, 89, 150-157.

126. Zhang, H.; Xu, W.; Guo, J.; He, Z.; Ma, M. Coordinated responses of phytochelatins and metallothioneins to heavy metals in garlic seedlings. Plant Sci. 2005, 169, 1059-1065.

127. Bhargava, P.; Srivastava, A.K.; Urmil, S.; Rai, L.C. Phytochelatin plays a role in UV-B tolerance in $\mathrm{N}_{2}$-fixing cyanobacterium Anabaena doliolum. J. Plant Physiol. 2005, 162, 1220-1225. 
128. Chaurasia, N.; Mishra, Y.; Rai, L.C. Cloning expression and analysis of phytochelatin synthase (pcs) gene from Anabaena sp. PCC 7120 offering multiple stress tolerance in Escherichia coli. Biochem. Bioph. Res. Commun. 2008, 376, 225-230.

129. Seki, M.; Narusaka, M.; Ishida, J.; Nanjo, T.; Fujita, M.; Oono, Y.; Kamiya, A.; Nakajima, M.; Enju, A.; Sakurai, T.; et al. Monitoring the expression profiles of 7000 Arabidopsis genes under drought, cold and high-salinity stresses using a full-length cDNA microarray. Plant J. 2002, 31, 279-292.

130. Stroiński, A.; Chadzinikolau, T.; Giżewska, K.; Zielezińska, M. ABA or cadmium induced phytochelatin synthesis in potato tubers. Biol. Plantarum. 2010, 54, 117-120.

131. Peleg, Z.; Blumwald, E. Hormone balance and abiotic stress tolerance in crop plants. Curr. Opin. Plant Biol. 2011, 14, 290-295.

132. Gupta, D.K.; Huang, H.G.; Yang, X.E.; Razafindrabe, B.H.N.; Inouhe, M. The detoxification of lead in Sedum alfredii $\mathrm{H}$. is not related to phytochelatins but the glutathione. J. Hazard. Mater. 2010, 177, 437-444.

133. Jozefczak, M.; Remans, T.; Vangronsveld, J.; Cuypers, A. Glutathione is a key player in metal-induced oxidative stress defenses. Int. J. Mol. Sci. 2012, 13, 3145-3175.

134. Delalande, O.; Desvaux, H.; Godat, E.; Valleix, A.; Junot, C.; Labarre, J.; Boulard, Y. Cadmium - glutathione solution structures provide new insights into heavy metal detoxification. FEBS J. 2010, 277, 5086-5096.

135. Gusmão, R.; Ariño, C.; Díaz-Cruz, J.M.; Esteban, M. Electrochemical survey of the chain length influence in phytochelatins competitive binding by cadmium. Anal. Bioch. 2010, 406, 61-69.

136. Elviri, L.; Speroni, F.; Careri, M.; Mangia, A.; Sanità di Toppi, L.; Zottini, M. Identification of in vivo nitrosylated phytochelatins in Arabidopsis thaliana cells by liquid chromatography-direct electrospray-linear ion trap-mass spectrometry. J. Chromatogr. A 2010, 1217, 4120-4126.

137. Arasimowicz-Jelonek, M.; Floryszak-Wieczorek, J.; Gwóźdź, E.A. The message of nitric oxide in cadmium challenged plants. Plant Sci. 2011, 181, 612-620.

138. De Vos, C.H.R.; Vonk, M.J.; Vooijs, R.; Schat, H. Glutathione depletion due to copper-induced phytochelatin synthesis causes oxidative stress in Silene cucubalus. Plant Physiol. 1992, 98, 853-858.

139. Seth, C.S.; Misra, V.; Chauhan, L.K.S. Accumulation, detoxification, and genotoxicity of heavy metals in indian mustard (Brassica juncea L.). Int. J. Phytoremediat 2012, 14, 1-13.

140. Gao, L.; Peng, K.; Xia, Y.; Wang, G.; Niu, L.; Lian, C.; Shen, Z. Cadmium and manganese accumulation in Phytolacca americana L. and the roles of non-protein thiols and organic acids. Int. J. Phytoremed. 2013, 15, 307-319.

141. Wang, F.; Wang, Z.; Zhu, C. Heteroexpression of the wheat phytochelatin synthase gene (TaPCS1) in rice enhances cadmium sensitivity. Acta Biochim. Biophys. Sin. 2012, 44, 886-893.

142. Queval, G.; Foyer, C. Redox regulation of photosynthetic gene expression. Phil. Trans. R. Soc. B 2012, 367, 3475-3485.

143. Vivancos, P.D.; Wolff, T.; Markovic, J.; Pallardó, F.V.; Foyer, C.H. A nuclear glutathione cycle within the cell cycle. Biochem. J. 2010, 431, 169-178. 
144. Bellomo, G.; Palladini, G.; Vairetti, M. Intranuclear distribution, function and fate of glutathione and glutathione-S-conjugate in living rat hepatocytes studied by fluorescence microscopy. Microsc. Res. Tech. 1997, 36, 243-252.

145. García-Giménez, J.L.; Markovic, J.; Dasí, F.; Queval, G.; Foyer, C.H.; Pallardó, F.V. Nuclear glutathione. Biochim. Biophys. Acta 2012, doi:10.1016/j.bbagen.2012.10.005.

146. Markovic, J.; Mora, N.J.; Broseta, A.M.; Gimeno, A.; de-la-Concepción, N.; Vina, J.; Pallardo, F.V. The depletion of nuclear glutathione impairs cell proliferation in $3 \mathrm{t} 3$ fibroblasts. PLoS One 2009, 4, e6413.

147. Zechmann, B.; Liou, L.-C.; Koffler, B.E.; Horvat, L.; Tomašić, A.; Fulgosi, H.; Zhang, Z. Subcellular distribution of glutathione and its dynamic changes under oxidative stress in the yeast Saccharomyces cerevisiae. FEMS Yeast Res. 2011, 11, 631-642.

148. Queval, G.; Jaillard, D.; Zechmann, B.; Noctor, G. Increased intracellular $\mathrm{H}_{2} \mathrm{O}_{2}$ availability preferentially drives glutathione accumulation in vacuoles and chloroplasts. Plant Cell Environ. 2011, 34, 21-32.

149. Vivancos, P.D.; Dong, Y.; Ziegler, K.; Markovic, J.; Pallardó, F.V.; Pellny, T.K.; Verrier, P.J.; Foyer, C.H. Recruitment of glutathione into the nucleus during cell proliferation adjusts whole-cell redox homeostasis in Arabidopsis thaliana and lowers the oxidative defence shield. Plant J. 2010, 64, 825-838.

150. Guillas, I.; Zachowski, A.; Baudouin, E. A matter of fat: Interaction between nitric oxide and sphingolipid signaling in plant cold response. Plant Signal. Behav. 2011, 6, 140-142.

151. De Pinto, M.C.; Paradiso, A.; Leonetti, P.; de Gara, L. Hydrogen peroxide, nitric oxide and cytosolic ascorbate peroxidase at the crossroad between defence and cell death. Plant J. 2006, 48, 784-795.

152. Gaupels, F.; Kuruthukulangarakoola, G.T.; Durner, J. Upstream and downstream signals of nitric oxide in pathogen defence. Curr. Opin. Plant Biol. 2011, 14, 707-714.

153. Sandalio, L.M.; Rodríguez-Serrano, M.; Gupta, D.K.; Archilla, A.; Romero-Puertas, M.C.; del Río, L.A. Reactive Oxygen Species and Nitric Oxide in Plants Under Cadmium Stress. In From Toxicity to Signaling Environmental Adaptations and Stress Tolerance of Plants in the Era of Climate Change; Ahmad, P., Prasad, M.N.V., Eds.; Springer: New York, NY, USA, 2012; pp. 199-215.

154. Arasimowicz, M.; Floryszak-Wieczorek, J.; Milczarek, G.; Jelonek, T. Nitric oxide, induced by wounding, mediates redox regulation in pelargonium leaves. Plant Biol. 2009, 11, 650-663.

155. Xu, J.; Wang, W.; Sun, J.; Zhang, Y.; Ge, Q.; Du, L.; Yin, H.; Liu, X. Involvement of auxin and nitric oxide in plant Cd-stress responses. Plant Soil. 2011, 346, 107-119.

156. Siddiqui, M.H.; Mohammad, F.; Khan, M.M.A.; Al-Whaibi, M.H. Cumulative effect of nitrogen and sulphur on Brassica juncea L. genotypes under $\mathrm{NaCl}$ stress. Protoplasma 2012, 249, 139-153.

157. Corpas, F.J.; Leterrier, M.; Valderrama, R.; Airaki, M.; Chaki, M.; Palma, J.M.; Barroso, J.B. Nitric oxide imbalance provokes a nitrosative response in plants under abiotic stress. Plant Sci. 2011, 181, 604-611.

158. Sueishi, Y.; Hori, M.; Kita, M.; Kotake, Y. Nitric oxide (NO) scavenging capacity of natural antioxidants. Food Chem. 2011, 129, 866-870. 
159. Stamler, J.S.; Lamas, S.; Fang, F.C. Nitrosylation: The prototypic redox-based signaling mechanism. Cell. 2001, 106, 675-683.

160. Baudouin, E. The language of nitric oxide signalling. Plant Biol. 2011, 13, 233-242.

161. Leterrier, M.; Chaki, M.; Airaki, M.; Valderrama, R.; Palma, J.M.; Barroso, J.B.; Corpas, F.J. Function of S-nitrosoglutathione reductase (GSNOR) in plant development and under biotic/abiotic stress. Plant Signal. Behaviour. 2011, 6, 789-793.

162. Lindermayr, C.; Sell, S.; Muller, B.; Leister, D.; Durner, J. Redox regulation of the NPR1-TGA1 system of Arabidopsis thaliana by nitric oxide. Plant Cell 2010, 22, 2894-2907.

163. Yu, M.; Yun, B.W.; Spoel, S.H.; Loake, G.J. A sleigh ride through the SNO: Regulation of plant immune function by protein S-nitrosylation. Curr. Opin. Plant Biol. 2012, 15, 424-430.

164. Serpa, V.; Vernal, J.; Lamattina, L.; Grotewold, E.; Cassia, R.; Terenzi, H. Inhibition of AtMYB2 DNA-binding by nitric oxide involves cysteine S-nitrosylation. Biochem. Biophys. Res. Commun. 2007, 361, 1048-1053.

165. Espunya, M.C.; de Michele, R.; Gómez-Cadenas, A.; Martínez, M.C. S-Nitrosoglutathione is a component of wound- and salicylic acid-induced systemic responses in Arabidopsis thaliana. J. Exp. Bot. 2012, 63, 3219-3227.

166. Molassiotis, A.; Tanou, G.; Diamantidis, G. NO says more than 'YES' to salt tolerance: Salt priming and systemic nitric oxide signaling in plants. Plant Signal. Behaviour. 2010, 5, 209-212.

167. Wang, H.; Liang, X.; Wan, Q.; Wang, X.; Bi, Y. Ethylene and nitric oxide are involved in maintaining ion homeostasis in Arabidopsis callus under salt stress. Planta 2009, 230, 293-307.

168. Meyer, Y.; Belin, C.; Delorme-Hinoux, V.; Reichheld, J.P.; Riondet, C. Thioredoxin and glutaredoxin systems in plants: Molecular mechanisms, crosstalks, and functional significance. Antioxid. Redox Sign. 2012, 17, 1124-1160.

169. Lemaire, S.D.; Michelet, L.; Zaffagnini, M.; Massot, V.; Issakidis-Bourguet, E. Thioredoxins in chloroplasts. Curr. Genet. 2007, 51, 343-365.

170. Schürmann, P.; Buchanan, B.B. The Ferredoxin/Thioredoxin system of oxygenic photosynthesis. Antioxid. Redox Sign. 2008, 10, 1235-1274.

171. Nuruzzaman, M.; Sharoni, A.M.; Satoh, K.; Al-Shammari, T.; Shimizu, T.; Sasaya, T.; Omura, T.; Kikuchi, S. The thioredoxin gene family in rice: Genome-wide identification and expression profiling under different biotic and abiotic treatments. Biochem. Biophys. Res. Commun. 2012, 423, 417-423.

172. Fatehi, F.; Hosseinzadeh, A.; Alizadeh, H.; Brimavandi, T. The proteome response of Hordeum spontaneum to salinity stress. Cereal Res. Commun. 2012, 1-10.

173. Sanz-Barrio, R.; Millán, A.F.S.; Carballeda, J.; Corral-Martínez, P.; Seguí-Simarro, J.M.; Farran, I. Chaperone-like properties of tobacco plastid thioredoxins $\mathrm{f}$ and m. J. Exp. Bot. 2012, 63, 365-379.

174. Lakhssassi, N.; Doblas, V.G.; Rosado, A.; del Valle, A.E.; Posé, D.; Jimenez, A.J.; Castillo, A.G.; Valpuesta, V.; Borsani, O.; et al. The Arabidopsis tetratricopeptide thioredoxin-like gene family is required for osmotic stress tolerance and male sporogenesis. Plant Physiol. 2012, 158, 1252-1266.

175. Prasad, B.D.; Goel, S.; Krishna, P. In silico identification of carboxylate clamp type tetratricopeptide repeat proteins in Arabidopsis and Rice as putative co-chaperones of Hsp90/Hsp70. PLoS One 2010, 5, e12761. 
176. Chae, H.B.; Moon, J.C.; Shin, M.R.; Chi, Y.H.; Jung, Y.J.; Lee, S.Y.; Nawkar, G.M.; Jung, H.S.; Hyun, J.K.; Kim, W.Y.; et al. Thioredoxin reductase type C (NTRC) orchestrates enhanced thermotolerance to Arabidopsis by its redox-dependent holdase chaperone function. Mol. Plant 2013, 6, 323-336.

177. Rampitsch, C.; Bykova, N. V. Proteomics and plant disease: Advances in combating a major threat to the global food supply. Proteomics 2012, 12, 673-690.

178. Chi, Y.H.; Kim, S.Y.; Jung, I.J.; Shin, M.R.; Jung, Y.J.; Park, J.H.; Lee, E.S.; Maibam, P.; Kim, K.S.; Park, J.H.; et al. Dual functions of Arabidopsis sulfiredoxin: Acting as a redox-dependent sulfinic acid reductase and as a redox-independent nuclease enzyme. FEBS Lett. 2012, 586, 3493-3499.

179. Kumar, B.; Singla-Pareek, S.L.; Sopory, S.K. Glutathione Homeostasis: Crucial for Abiotic Stress Tolerance in Plants. In Abiotic Stress Adaptation in Plants; Pareek, A., Sopory, S.K., Bohnert, H.J., Govindjee, Eds.; Springer: Dordrecht, The Netherlands, 2010; pp. 263-282.

180. Lemaire, S.D.; Guillon, B.; Maréchal, P.; Keryer, E.; Miginiac-Maslow, M.; Decottignies, P. New thioredoxin targets in the unicellular photosynthetic eukaryote Chlamydomonas reinhardtii. Proc. Natl. Acad. Sci. USA 2004, 101, 7475-7480.

181. Zaffagnini, M.; Bedhomme, M.; Marchand, C.H.; Couturier, J.; Gao, X.H.; Rouhier, N.; Trost, P.; Lemaire. S.D. Glutaredoxin S12: Unique properties for redox signaling. Antioxid. Redox Sign. 2012, 16, 17-32.

182. Mortimer, J.C.; Laohavisit, A.; Macpherson, N.; Webb, A.; Brownlee, C.; Battey, N.H.; Davies, J.M. Annexins: Multifunctional components of growth and adaptation. J. Exp. Bot. 2008, 59, 533-544.

183. Konopka-Postupolska, D.; Clark, G.; Goch, G.; Debski, J.; Floras, K.; Cantero, A.; Fijolek, B.; Roux, S.; Hennig, J. The role of annexin 1 in drought stress in Arabidopsis. Plant Physiol. 2009, 150, 1394-1410.

184. Nadeau, P.J.; Charette, S.J.; Toledano, M.B.; Landry, J. Disulfide bond mediated multimerization of Ask1 and its reduction by thioredoxin-1 regulate $\mathrm{H}_{2} \mathrm{O}_{2}$-induced c-Jun $\mathrm{NH}_{2}$-terminal kinase activation and apoptosis. Mol. Biol. Cell 2007, 18, 3903-3913.

185. Clark, G.; Konopka-Postupolska, D.; Hennig, J.; Roux, S. Is annexin 1 a multifunctional protein during stress responses? Plant Signal. Behav. 2010, 5, 303-307.

(C) 2013 by the authors; licensee MDPI, Basel, Switzerland. This article is an open access article distributed under the terms and conditions of the Creative Commons Attribution license (http://creativecommons.org/licenses/by/3.0/). 